\title{
Generic principles of crack-healing ceramics
}

\author{
Peter GREIL* \\ Department of Materials Science (Glass and Ceramics), University of Erlangen-Nuernberg, \\ Martensstr. 5, Erlangen 91058, Germany
}

Received: September 21, 2012; Revised: October 19, 2012; Accepted: October 20, 2012

CThe Author(s) 2012. This article is published with open access at Springerlink.com

\begin{abstract}
Ceramic materials able to heal manufacture or damage induced microstructure defects might trigger a change in paradigm for design and application of load bearing ceramics. This work reviews thermodynamic and kinetic aspects governing the regeneration of solid contact able to transfer stress between disrupted crack surfaces in ceramics. Major crack healing processes include perturbation of crack-like pores followed by sintering of isolated pores, as well as reaction with an environmental atmosphere and filling of the crack space with an oxidation product. Since thermally activated solid state reactions require elevated temperatures which may exceed $1000{ }^{\circ} \mathrm{C}$, processes able to trigger crack healing at lower temperatures are of particular interest for transferring into engineering applications. Generic principles of microstructure modifications able to facilitate crack repair at lower temperatures will be considered: (i) acceleration of material transport by grain boundary decoration and grain size reduction, and (ii) reduction of thermal activation barrier by repair filler activation. Examples demonstrating crack healing capability include oxidation reaction of low energy bonded intercalation metal from nano-laminate MAX phases and catalyzed surface nitridation of polymer derived ceramics containing repair fillers.
\end{abstract}

Key words: crack healing; microstructure modifications; oxidation healing; MAX phases; preceramic polymers

\section{Introduction}

Ceramic materials able to repair flaws and cracks and recover initial properties constitute a vital field of materials science that gained in significance recently [1-5]. Advanced engineering as well as functional (electrical, magnetic, chemical, nuclear, biomedical) ceramics are susceptible to damage cracks, which may

* Corresponding author.

E-mail: peter.greil@ww.uni-erlangen.de form on the surface as well as deeply in the bulk caused by machining, overloading, creep, fatigue, or friction (Fig. 1). Many ceramic components are stressed mechanically or thermally with high cycle numbers $\left(>10^{6}\right.$ to $10^{9}$ per lifetime $)$ - for instance piezoelectric-actors, components in piston engines and gas turbines including their temperature and corrosion protection systems, diesel particle filter systems, mounting and friction systems, also medical joint implants. Regardless of the application, once cracks have formed within ceramic materials, the integrity of the structure is significantly compromised. While 

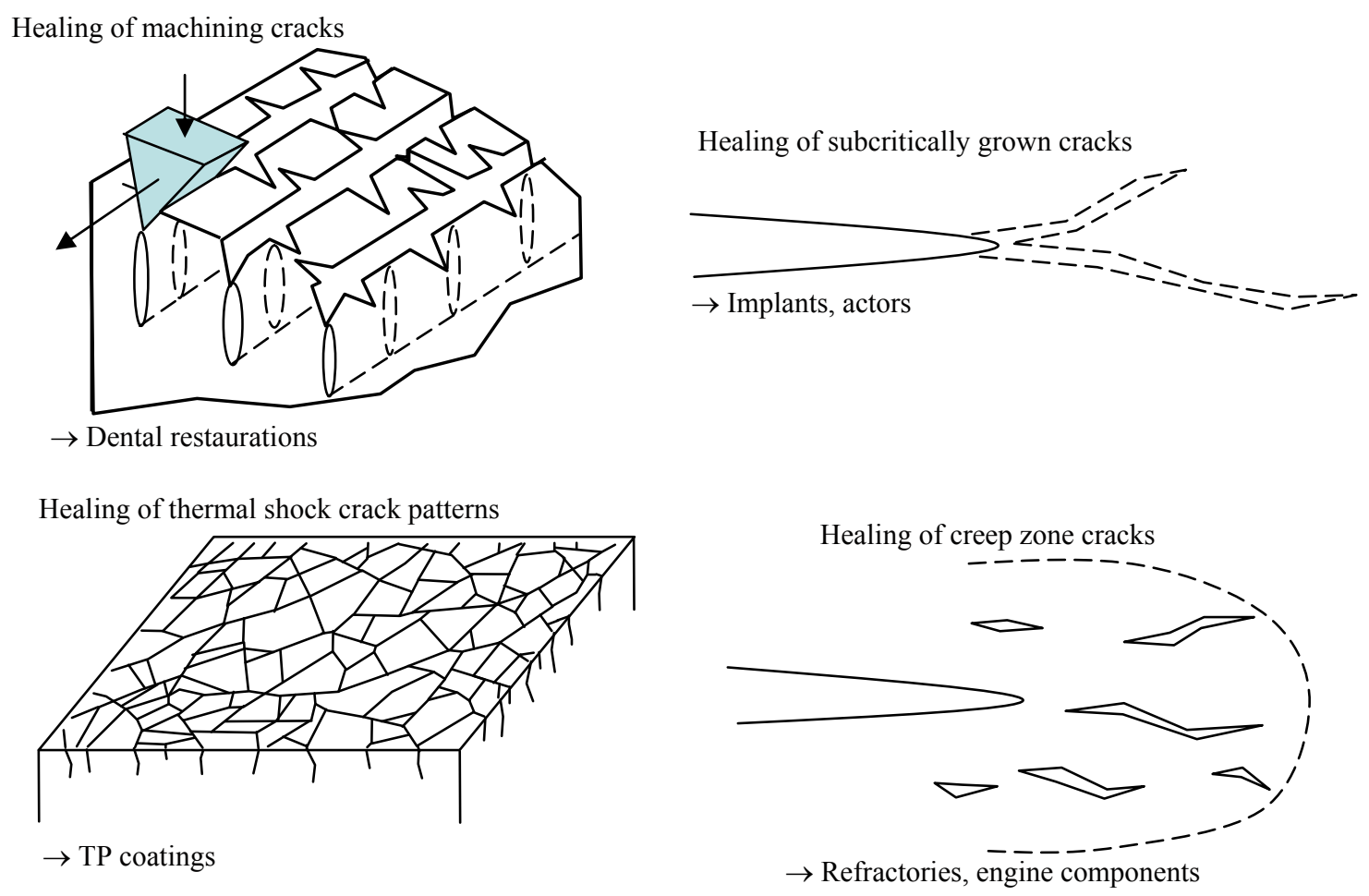

Fig. 1 Examples of crack formation in ceramic materials induced by surface machining, thermal shock loading, slow crack growth and creep crack formation.

cracks of critical size immediately cause catastrophic failure upon loading slow crack growth (e.g., subcritical crack growth) at subcritical stress intensities can cause strength degradation with time and finally delayed failure. The ceramic components are limited in their lifetime, load carrying capacity and reliability by accumulated damages. In addition to increasing the toughness, the concept of healing of structural defects (cracks and pores) is an emerging approach to improve significantly the performance and reliability of ceramic components and devices.

Ceramics able to heal cracks (often denoted as (self-)repair or (self-)healing materials) are inspired by geological systems in which pressure solution and frictional healing triggers fault zone strengthening [6] as well as by biological systems in which damage triggers an autonomic healing response [1]. This new paradigm in materials design has led to several exciting inter-disciplinary approaches involving chemistry, mechanics, and materials processing to successfully incorporate crack healing functionality in non-biological materials [7]. Ab initio calculations [8], Monte-Carlo simulations [9], and continuum models [10] were applied to describe the healing reaction at various length scales ranging from the atomistic level to the macroscopic component size. Phenomenological rate equations based on experimental work or numerical simulations were derived which describe crack healing and strength recovery for various damage scenarios and repair reaction mechanisms [11]. From molecular-based reversible bonding schemes to macroscale structural approaches using hollow capsules or fibres, there currently exist a number of concepts at various stages of development for defect healing in polymers, composites, and concretes [12]. Compared to polymeric systems, however, healing of cracks in ceramics is difficult to achieve at moderate temperatures $\left(<1000{ }^{\circ} \mathrm{C}\right)$. High activation energies for solid state diffusion inhibit long range material transport required to heal macro-cracks. Furthermore, crack surface relaxation phenomena triggered by the ionic and covalent bonding character in ceramics inhibit healing of nano-cracks [13]. Work on damage regeneration in brittle ceramic materials therefore mainly referred to high temperature healing processes [14]. Important mechanisms governing crack healing in ceramics at elevated temperatures include crack regression by diffusional controlled sintering, crack wake rebonding by viscous flow controlled redistribution of an intergranular glass phase, and 
filling the crack opening space by an oxidation reaction product. The formation of an eutectic melt as well as the local particle rearrangement induced by a phase transition $\left(\mathrm{ZrO}_{2}\right.$, tetr $\rightarrow \mathrm{ZrO}_{2}$, mcl $)$ was considered as further healing mechanisms in multi-component and multi-phase ceramic materials [15].

Crack healing was studied on single crystal systems $[16,17]$, polycrystalline materials $[10,18]$ as well as amorphous glasses [18,19]. Most studies were concerned with surface cracks which were introduced by thermal shocking, indenting, impacting, cleaving, inscribing, or stressing of a precrack [20]. Early work focused on crack healing of surface cracks of polycrystalline $\mathrm{UO}_{2}$ [21,22], $\mathrm{Al}_{2} \mathrm{O}_{3}$ [23] and $\mathrm{MgO}$ [24]. Since then, a large number of ceramic materials were demonstrated to exhibit crack healing capability including silicon carbide [25,26], silicon nitride [27,28], single crystalline sapphire [29], alumina $[15,30,31]$, mullite [32,33], zirconia [34], or MAS glass ceramics [35]. The temperatures to initiate healing reaction, however, were found to exceed 0.7-0.9 of the melting temperature of single crystals or equal the sintering temperature of polycrystalline ceramics. The activation energy derived from kinetic analyses corresponds to values typical for surface and grain boundary diffusion controlled material transport and the rate of crack healing was equivalent to that of grain growth [21]. Lower temperatures of $1000-1300{ }^{\circ} \mathrm{C}$ were reported for oxidation induced crack healing of surface flaws in a variety of Si-containing ceramics where viscous $\mathrm{SiO}_{2}$ and silicate based reaction products are able to fill the space between crack walls [36-38]. Ceramics containing more than $10 \mathrm{vol} \%$ of $\mathrm{SiC}$ particles or whiskers were reported to exhibit efficient crack healing ability triggered by $\mathrm{SiC}$ oxidation reaction [39] resulting in a pronounced improvement of strength and reliability as well as reduction of the manufacturing costs [40,41]. Oxidation in air as well as viscous flow were successfully demonstrated to trigger healing reaction in ceramic matrix [42] and in glass matrix [43] fiber composites even at relatively low temperatures of $500-600{ }^{\circ} \mathrm{C}$. Filling very large surface cracks $(>2 \mathrm{~mm})$ prepared on alumina with a borosilicate glass at $1500{ }^{\circ} \mathrm{C}$ was demonstrated to yield even stronger material than the mother material which was attributed to thermal expansion mismatch induced compressive surface stress [44]. Critical thresholds for oxygen partial pressure [39] as well as constant and cyclic stress loading were reported to control the recovery of strength $[45,46]$.
In the following, thermodynamic and kinetic aspects of ceramics with the capability of repairing crack wake disruption either by solid state reactions (internal and surface cracks) and by vapour solid oxidation reactions (surface cracks and pores) will be reviewed. After discussing microstructure based models for evolution of crack size reduction and strength recovery with time, temperature and gas pressure, emphasis will be given to microstructure modifications able to achieve crack healing at lower temperatures $\left(<1000{ }^{\circ} \mathrm{C}\right)$. Enhancement of material transport and stimulation of repair filler reactivity will be considered and examples for accelerated healing will be presented.

\section{Thermodynamic aspects}

Crack propagation rate $\partial c / \partial t$ in brittle ceramic materials subjected to stress intensities exceeding the fracture toughness, e.g., $K \geqslant K_{\mathrm{c}}$, approaches propagation velocity of elastic waves, e.g., sound velocity of solid matter (brittle fracture). At $K<K_{\mathrm{c}}$, however, change of flaw size will be controlled by kinetic constraints, e.g., thermally activated lattice vibration and material transport (atoms, vacancies, molecules) resulting in significantly slower crack propagation rates (slow or subcritical crack growth). Depending on the net local driving force even a negative growth rate, e.g., crack regression was postulated [47] and confirmed by numerous observations of high temperature crack healing in ceramics. Following thermodynamic considerations of crack propagation conditions in brittle materials [48] net growth rate $\partial c / \partial t$ can be formulated, at least near the equilibrium between crack advance and regression, by

$$
\frac{\partial c}{\partial t}=k_{0} \exp \left(-\frac{\Delta G^{*}}{k_{\mathrm{B}} T}\right) \sinh \left[\frac{\alpha\left(G_{\mathrm{c}}-\Delta G_{\text {heal }}\right)}{k_{\mathrm{B}} T}\right]
$$

The first term accounts for the kinetic limitation where pre-exponential constant $k_{0}$ is given by fundamental lattice vibration parameters $\left(k_{0}=v a k_{\mathrm{B}} T / h\right.$ with $v$ a vibrational frequency, $a$ the distance the crack advances when one bond is broken, $k_{\mathrm{B}}$ Boltzmann constant, $T$ the absolute temperature and $h$ Planck constant), and $\Delta G^{*}$ is the activation barrier of the rate controlling process. The second term expresses the net force driving either crack advance $\left(G_{\mathrm{c}}>\Delta G_{\text {heal }}\right)$ or regression $\left(G_{\mathrm{c}}<\Delta G_{\text {heal }}\right) . \alpha$ is a constant having the status of an activation area for the kinetic crack motion 
[49], $G_{\mathrm{c}}$ denotes Irwin's elastic energy release rate upon crack advance per unit area and $\Delta G_{\text {heal }}$ accounts for Gibbs free energy release associated with crack regression per unit area.

$$
\Delta G_{\text {heal }}=\Delta G_{\text {surf }}+\Delta G_{\text {el }}+\Delta G_{\text {chem }}
$$

$\Delta G_{\text {heal }}$ will be governed by conversion of surface to grain boundary energy $\Delta G_{\text {surf, }}$, relaxation of elastic (pressure) strain energy $\Delta G_{\mathrm{el}}$, and in the case of reaction phase formation gain in chemical energy $\Delta G_{\text {chem }}$. Without applying an external compressive stress $\left(\Delta G_{\mathrm{el}}=0\right)$ and if no environmental effect (e.g., oxidation) or phase formation reaction occurs $\left(\Delta G_{\text {chem }}=0\right)$, crack healing will be driven by reduction of surface energy only. The condition for crack healing $G_{\mathrm{c}}<\Delta G_{\text {surf }}$ equals $\pi \sigma^{2} c / E<\left(2 \gamma_{\mathrm{s}}-\gamma_{\mathrm{gb}}\right)$ where $\sigma$ is the applied load, $E$ is Young's modulus, $\gamma_{\mathrm{s}}$ and $\gamma_{\mathrm{gb}}$ are the surface and grain boundary energy, respectively. This condition implicates the existence of a critical tensile loading stress beyond which no healing may occur. Indeed, experimental results on oxidation induced healing of $\mathrm{Si}_{3} \mathrm{~N}_{4} / \mathrm{SiC}$ composites revealed threshold cyclic and constant stresses of $300 \mathrm{MPa}$ (which was $75 \%$ of the bending strength) below which pre-cracked specimens recovered their initial bending strength at healing temperatures exceeding $1000{ }^{\circ} \mathrm{C}$ [45].

For the case of crack healing by sintering, however, this threshold stress is expected to be very small. Thus, for example, for a reference crack of area $A_{\mathrm{c}}=M_{\mathrm{w}} /(\rho \cdot d)$ where $M_{\mathrm{w}}$ is the molar weight, $\rho$ the density and $d$ corresponds to a mean particle diameter of $1 \mu \mathrm{m}$ and typical values of $\left(2 \gamma_{\mathrm{s}}-\gamma_{\mathrm{gb}}\right)$ varying in the range of $1-5 \mathrm{~J} / \mathrm{m}^{2}$ for oxide as well as non-oxide ceramics, extremely small values of $\Delta G_{\text {heal }} \ll 1 \mathrm{~kJ} / \mathrm{mol}$ (for example $\alpha-\mathrm{Al}_{2} \mathrm{O}_{3} \quad 0.13 \mathrm{~kJ} / \mathrm{mol}, \quad \mathrm{t}-\mathrm{ZrO}_{2} \quad 0.07 \mathrm{~kJ} / \mathrm{mol}$, $\beta$-SiC $0.03 \mathrm{~kJ} / \mathrm{mol}$ ) are derived as driving forces for crack closure of relaxed crack surfaces. On the other hand, high values of activation energy $\Delta G^{*}$ where measured experimentally for crack healing reactions. Except for fluid flow controlled crack healing $\left(\Delta G^{*}<100 \mathrm{~kJ} / \mathrm{mol}\right)$ [50], significantly higher activation energies were reported for vapour-solid oxidation reaction $\left(\Delta G^{*}<400 \mathrm{~kJ} / \mathrm{mol}\right)$, and solid state matter transport through viscous flow of an amorphous inter-granular phase $\left(\Delta G^{*}<500 \mathrm{~kJ} / \mathrm{mol}\right)$, surface diffusion $\left(\Delta G^{*}<600 \mathrm{~kJ} / \mathrm{mol}\right)$ and grain boundary diffusion $\left(\Delta G^{*}<800 \mathrm{~kJ} / \mathrm{mol}\right)[10,51,52]$. Compared to the repair capacity of polymers and polymer composite materials which are able to regenerate cracks near ambient temperature or supported by UV radiation catalysis [7,53], repair reactions in ceramic materials therefore require elevated temperatures to overcome the high activation energy barrier. The temperatures to initiate solid state healing reaction within a reasonable time period of a few hours $(<10 \mathrm{~h})$ were found to exceed $0.7-0.9$ of the melting temperature of single crystals (e.g., sapphire $\left(\mathrm{Al}_{2} \mathrm{O}_{3}\right) T_{\text {healing }}=1800{ }^{\circ} \mathrm{C}[29]$ or equal the level of sintering temperature of polycrystalline ceramics ( $T_{\text {healing }}$ of $\mathrm{UO}_{2}>1400{ }^{\circ} \mathrm{C}$, $\left.\mathrm{Al}_{2} \mathrm{O}_{3}>1400{ }^{\circ} \mathrm{C}, \mathrm{MgO}>1600{ }^{\circ} \mathrm{C}\right)$ [22,54]. Applying microwave heating instead of conventional heating was reported to give rise for enhanced healing kinetics [55]. Figure 2 summarizes experimental data of healing time and temperature relation for selected ceramic systems.

Though the thermodynamics considerations suggest the propability of crack healing, it is the detailed kinetics on the crack-tip scale, which will determine if healing will actually occur [47]. When the porosity is of non-equilibrium shape, e.g., crack-like, gradients in chemical potential $\nabla \mu$ due to surface tension will always exist and provide local driving force for crack regression [56]. In the absence of an applied stress (relaxed crack) and for the case of material transport controlled healing reaction steady state crack regression rate may be expressed by

$$
-\frac{\partial c}{\partial t}=\frac{D_{0}^{\text {eff }}}{k_{\mathrm{B}} T} \exp \left(-\frac{\Delta G^{*}}{k_{\mathrm{B}} T}\right) \nabla \mu
$$

in which $D_{0}{ }^{\text {eff }}$ denotes the effective diffusivity

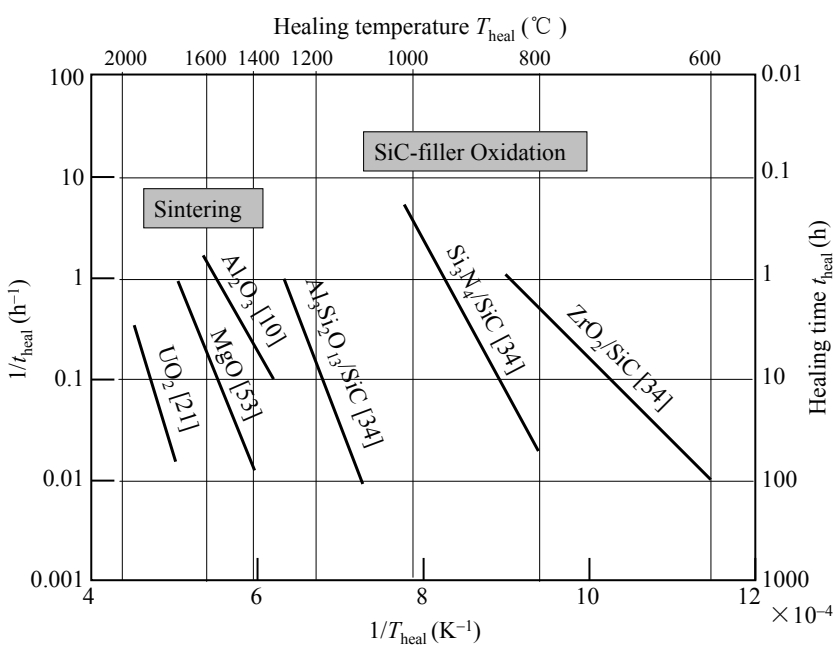

Fig. 2 Healing time versus healing temperature relation of different ceramic systems (healing time corresponds to more than $80 \%$ recovery of strength). 
pre-exponential factor for surface, grain boundary, or lattice diffusion, respectively, subjected to local microstructure constraints (e.g., grain size, grain boundary width). Using Kelvin equation, the chemical potential of an atom at a curved surface is related to the radius of curvature and the potential gradient is given by

$$
\nabla \mu \equiv \gamma_{\mathrm{s}} \Omega\left(\frac{1}{r_{\mathrm{c}}}-\frac{1}{r_{0}}\right)
$$

where $\Omega$ is the atomic volume, $r_{\mathrm{c}}$ is the neck radius at the crack tip and $r_{0}$ of the outer surface, respectively (see Fig. 3). Since crack geometry may vary as for example crack tip curvature (neck radius $r_{\mathrm{c}}$ ) may change with particle size and temperature, the local driving force $\nabla \mu\left(\propto 1 / r_{\mathrm{c}}\right)$ and hence crack regression rates for micro-cracks ( $r_{\mathrm{c}}$ is small) are supposed to be higher compared to large macro-cracks ( $r_{\mathrm{c}}$ is large) and a critical crack geometry may exist for healing to occur in a specific material at a given temperature. For the case of vapour transport from the surface to the crack tip controlling crack filling by an oxidation reaction

$$
\nabla \mu \equiv k_{\mathrm{B}} T \ln \left(\frac{p}{p_{0}}\right)
$$

where $p_{0}$ and $p$ denote the vapour pressure at the source (crack mouth) and sink (crack tip), respectively [49] (Fig. 4). Since $p / p_{0}$ will be lower in deep surface cracks compared to near surface cracks, differences in crack filling rate may occur depending on crack geometry and location.

\section{Kinetic aspects}

\subsection{Solid state crack healing}

Morphological observations indicate that healing of a crack like defect during thermal treatment may be separated into several steps [57]: (i) regression of the crack tip either as a continuous front or discontinuous pinching-off of the crack, (ii) formation of cylindrical pores, (iii) break-up of the cylindrical voids due to perturbations in their radius (Rayleigh instability) and ovulation of spherical pores, and (iv) shrinkage (elimination) of isolated pores (Fig. 3). The initial stage of crack healing which represents primarily the pinching-off process of a crack-like pore, has been treated theoretically by Nichols and Mullins using perturbation theory [16]. Though the understanding of initial crack instability is still limited, Gupta [57]

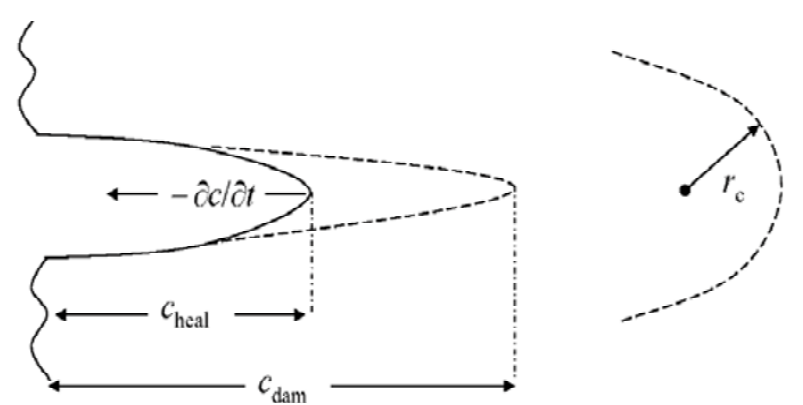

(a) Crack regression
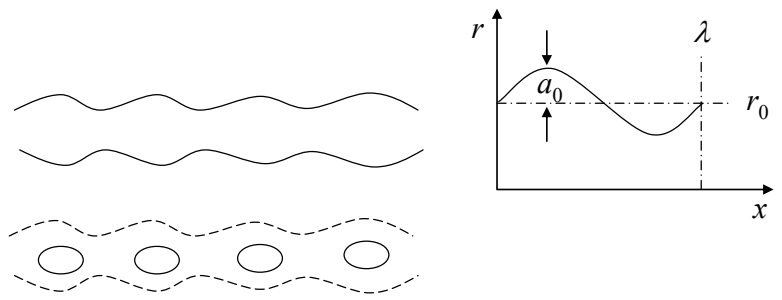

(b) Pore perturbation and sintering

Fig. 3 Scheme of high temperature stimulated crack healing reactions: (a) crack regression and (b) pore perturbation (initial stage) and isolated pore sintering (final stage).

proposed that continuous crack front regression will predominate when the material remains stress-free; if the material retains a residual stress, crack pinching will prevail. In contrast to the initial state of healing the final process of isolated pore elimination was well documented in literature and a variety of kinetic models to describe time dependence of strength recovery were derived. These models consider different crack morphology (surface cracks, internal cracks, single cracks, and multiple crack patterns), crack formation (machining, inscribing, thermal quenching, extension of existing cracks), matter transport (surface, grain boundary and volume diffusion, viscous flow, vapour diffusion), microstructure (single and multiphase composition, grain size and shape, intergranular phase), stress distribution (applied compression stress, residual stresses, relaxed state), and environmental effects (vacuum, inert or oxidizing (air) atmosphere, humidity).

For the case of surface diffusion controlled crack healing in the initial stage of pore perturbation, Evans and Charles [10] formulated a model for healing kinetics assuming isotropic surface tension and parabolic crack shape. Extending this model for cracks of elliptical cross section, Hickmann and Evans [58] derived a modified power law expression for relating 
instantaneous crack size $c_{\text {heal }}$ with precracked crack size (damage) $c_{\text {dam }}$ and elapsed time $t$ by

$$
c_{\text {heal }} \approx c_{\text {dam }}\left[1-A_{m}\left(\frac{B t}{c_{\text {dam }}}\right)^{n}\right]
$$

$A_{m}$ and $n$ were expressed as functions of a scaling parameter $m$ which relates initial crack aperture to spacing of the tubular pore by $A_{m}=0.5[(3 m+7) / 2]^{4 /(3 m+7)}$ and $n=4 /(3 m+7)$. Based upon experimental observation of the healing process reasonable values of $m$ were found to range from 0 to 4 resulting in $A_{m} \approx 1.02-0.80$ and $n \approx 0.57-0.21$, respectively [58]. $B$ is given by the surface diffusivity term

$$
B=C \frac{D_{0, \mathrm{~s}} \gamma_{\mathrm{s}} \Omega^{2} \kappa}{k_{\mathrm{B}} T} \exp \left(-\frac{\Delta G^{*}}{k_{\mathrm{B}} T}\right)
$$

where $C$ is a constant depending on the crack geometry (e.g., driving force) and $\kappa$ is the number of diffusing species per unit surface area (usually take as $\Omega^{-2 / 3}$ ). Equation (6) indicates that the degree of crack regression $\left(c_{\text {dam }}-c_{\text {heal }}\right) / c_{\text {dam }}$, which equals 0 for no healing and 1 for complete healing, is expected to scale with a power law function of time.

Though Eq. (6) was derived for surface-diffusion controlled ovulation of initial crack-like pore, transition from initial stage of crack perturbation to later stage of isolated pore sintering may induce change of the rate controlling process from surface to grain boundary (or lattice) diffusion and coupling of different diffusion mechanisms [59]. Based on Dutton's analysis of isolated pore sintering [60], an expression for crack shrinkage governed by grain boundary diffusion (final stage healing) was formulated which is analogues to Eq. (6) except for $n=1$ and $C=C^{\prime}(\delta / d)$ where $\delta$ is the effective grain boundary width and $d$ is the grain size. The contribution resulting from volume diffusion can be accounted for by using an alternative expression [61] which leads to the same time-temperature dependence $(n=1)$, in the final stage but differing in the values of activation barrier. Analyses of a number of experimental crack healing data confirmed the general validity of Eq. (6) for characterization of timetemperature healing behaviour in polycrystalline ceramics where thermally activated condensed matter transport dominates crack regression $[10,19,20,22$, 50,62-65]. Moreover, viscous flow controlled healing may be described with similar functional form but replacing diffusivity $D$ by viscosity $\eta$ and $C=$
$C^{\prime \prime}\left(\delta^{3} / d^{3}\right)$ [64]. Assuming that the molecular motions required for atom transport controlling diffusion are similar to those controlling viscous flow, the diffusion coefficient $D$ relates to the viscosity $\eta$ according to Stokes-Einstein equation $\left(D=k_{\mathrm{B}} T /\left(r_{\mathrm{a}} \eta\right)\right.$ where $r_{\mathrm{a}}$ is the radius of diffusion atom species [65]). Grain boundary material transport by viscous flow, however, suffers from high activation barrier (earth alkaline alumosilicate glasses: $\Delta G^{*}>250 \mathrm{~kJ} / \mathrm{mol}$ [66], earh alkaline oxinitride glasses: $\Delta G^{*}>780 \mathrm{~kJ} / \mathrm{mol}$ [67]) observed in silicate and oxinitride amorphous phase compositions that are present in a number of liquid phase sintered ceramics. Furthermore, a cubic power dependence on boundary layer thickness and grain size $\left(\delta^{3} / d^{3}\right)$ require small grain size and a high fraction of intergranular amorphous phase in order to contribute significantly to the healing process (except for applying an external load).

Reduction of effective flaw size upon healing reaction induces a strength recovery with time. The fracture stress, $\sigma_{\mathrm{c}}$, is related to the crack length, $c$, through Griffith equation

$$
\sigma_{\mathrm{c}}=\frac{1}{Y} \frac{K_{\mathrm{c}}}{\sqrt{c}}
$$

where $Y$ is a dimensionless factor that depends on crack geometry and crack configuration (single crack or crack arrays), and $K_{\mathrm{c}}$ is the critical stress intensity factor (fracture toughness). If the component is subjected to load slow crack growth may occur and cause extension of initial crack size $c_{0}$ to $c_{\text {dam }}$ after time $t$

$$
c_{\mathrm{dam}}=c_{0}+F K^{m} t
$$

$F$ and $m$ are material dependent constants that characterize crack extension in the low stress intensity $(K)$ regime of slow crack growth. The isothermal kinetics of strength recovery governed by transport controlled healing reaction, e.g., perturbation and sintering, can now be obtained by substituting $c$ from Eqs. (6) and (9) into Eq. (8) by

$$
\left(\frac{\sigma_{\text {heal }}}{\sigma_{0}}\right)^{2} \approx \frac{c_{0}}{\left(c_{0}+A t\right)\left[1-\lambda(B t)^{n}\right]}
$$

where $\lambda$ is a constant depending on initial strength and toughness. For the case of an unloaded component, e.g., no slow crack growth $(A=0)$, a similar expression as derived in [10] follows

$$
1-\left(\frac{\sigma_{0}}{\sigma_{\text {heal }}}\right)^{2}=\lambda^{\prime}\left(\frac{Y \sigma_{0}}{K_{\mathrm{c}}}\right)^{2}(B t)^{n}
$$


Thus, a linear relation between $\log \left[1-\left(\sigma_{0} / \sigma_{\text {heal }}\right)^{2}\right]$ and $\log t$ with slope $n$ should apply. Initial recovery controlled by surface diffusion ovulation $n$ should approximately equal to 0.6 , however, late stage recovery was supposed to occur much more slowly [10]. Based on Dutton's model on sintering of crack like pores by grain boundary diffusion [60], a linear expression for final stage crack healing was derived with $n \approx 1$ [21,22]. Figure 4 shows the variation of fractional strength $\left(\sigma_{\text {heal }} / \sigma_{0}\right)$ with time calculated from Eq. (10) for the cases of slow crack growth only $(B=0)$, slow crack growth and simultaneous crack healing and crack healing of an unloaded crack $(K=0$, e.g., $A=0)$. It is obvious that with increasing values of $B$ which expresses the temperature dependent rate constant (Eq. (7)) strength recovery kinetics will be accelerated. Even fractional strength values $\left(\sigma_{\text {heal }} / \sigma_{0}\right)>1$ may be obtained if crack healing triggers regression of crack size below the size of the initial crack prior to slow crack growth.

\subsection{Oxidation reaction crack healing}

Surface cracks and pores are commonly more relevant to failure than internal cracks due to maximum stress concentration near the surface of a mechanically loaded component. Thus environmental effects such as oxidation, hydrolysis or reaction with $\mathrm{CO}_{2}, \mathrm{SO}_{3}$, etc. may have a profound influence on the extent of crack healing and strength recovery by formation of new phases filling the crack and pore space [68]. Microcracks in crystalline $\mathrm{SiO}_{2}$ (quartz) with a length of $100 \mu \mathrm{m}$ and a width of $10 \mu \mathrm{m}$ were completely

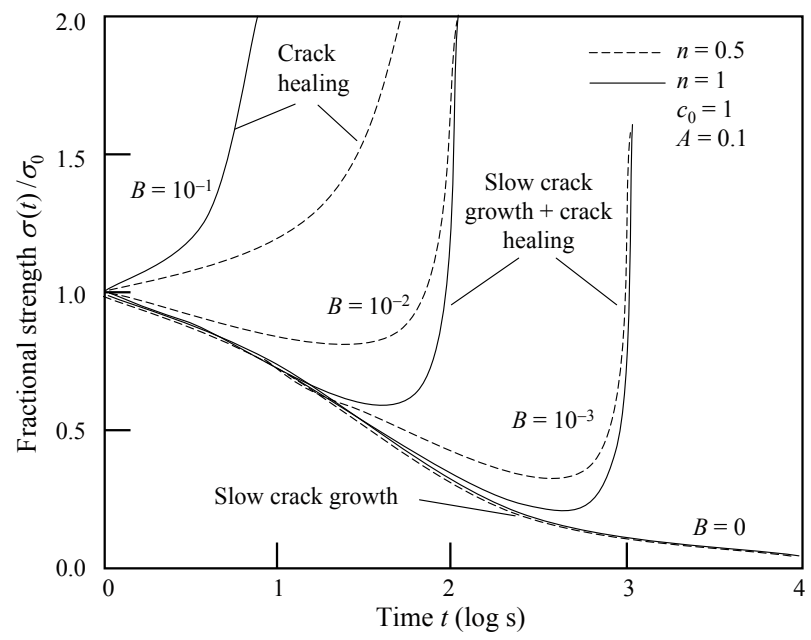

Fig. 4 Scheme of strength recovery evolution with time calculated for solid state crack healing (Eq. (10)). healed by exposure to a water pressure of $200 \mathrm{MPa}$ at $600{ }^{\circ} \mathrm{C}$ for $4 \mathrm{~h}[50]$. Strength recovery by hightemperature oxidation induced crack healing with environmental oxygen at elevated temperatures was reported from a number of non-oxide ceramics as well as oxide ceramics loaded with $\mathrm{SiC}[26,30,34$, 39-41,51,69-74]. For example, annealing of $\mathrm{SiC}$ reinforced $\mathrm{Al}_{2} \mathrm{O}_{3}$ nanocomposites in inert $\mathrm{Ar}$ atmosphere resulted in a strength increase of $50 \%$ relative to the unannealed specimen whereas annealing in air yielded a three-fold improvement in the indendation strength [69]. The pronounced recovery of strength was attributed to the formation of a silica rich glassy phase, which filled the crack space causing crack tip blunting and crack rebonding. Healing of transgranular cracks in $\mathrm{Si}_{3} \mathrm{~N}_{4}$ based ceramics exposed to air atmosphere was attributed either to the oxidation of the $\mathrm{Si}_{3} \mathrm{~N}_{4}$ grains forming a $\mathrm{SiO}_{2}$ glass at the crack surface or to the oxidation of intergranular phases $\left(2 \mathrm{SiO}_{2}+\mathrm{Y}_{2} \mathrm{O}_{3} \rightarrow \mathrm{Y}_{2} \mathrm{Si}_{2} \mathrm{O}_{7}\right)$ [75]. As a result healing could be achieved at temperatures as low as $600{ }^{\circ} \mathrm{C}$ after $100 \mathrm{~h}$ annealing. Based on TEM analyses, however, flow of vitreous intergranular phase followed by gradual crystallization was identified as another important mechanism which produced discontinuous vitreous bridging of glass phase in the crack wake [76].

Ternary $\mathrm{M}_{n+1} \mathrm{AX}_{n}$ phases of hexagonal crystal symmetry are distinguished by a unique alteration of metal bonded A-layers $(\mathrm{A}=\mathrm{A}$ group element) and $\mathrm{XM}_{6}$-octahedra layers $(\mathrm{M}=$ early transition metal and $\mathrm{X}=\mathrm{C}, \mathrm{N}$ ) differing in stacking sequence, e.g., $n=1$ to 6 [77-79]. Due to their nano-laminate structure MAX phase materials with $\mathrm{M}=\mathrm{Ti}$ and $\mathrm{A}=\mathrm{Si}, \mathrm{Al}$ exhibit superior machinability, excellent thermal shock resistance as well as good thermal and electrical conductivity, respectively. Moreover, the MAX phases were reported to exhibit capability of crack healing governed by oxidation of the metal elements [2]. Healing of surface cracks in air atmosphere was observed on $\mathrm{Ti}_{3} \mathrm{AlC}_{2}$ at $1100{ }^{\circ} \mathrm{C}$ with $\alpha-\mathrm{Al}_{2} \mathrm{O}_{3}$ filling the crack space [68]. Since crack healing efficiency was attributed to the preferential oxidation of the A-element MAX phase compositions containing higher A-element fractions, e.g., $n=1$ (H-phases) were postulated to exhibit improved crack healing behaviour. Thus, surface cracks up to a diameter of $10 \mu \mathrm{m}$ on single crystalline $\mathrm{Ti}_{2} \mathrm{AlC}$ could be healed at $1200{ }^{\circ} \mathrm{C}$ within a very short healing period of five minutes only [80]. Recent work on $\mathrm{V}_{2} \mathrm{AlC}$ supported by ab initio 
calculations of epitaxial phase boundary formation between $\alpha-\mathrm{Al}_{2} \mathrm{O}_{3}$ and $\mathrm{V}_{2} \mathrm{AlC}$ confirmed the excellent healing ability of $\mathrm{M}_{2} \mathrm{AlC}$ MAX phase [8]. Other ternary carbide phases such as for example $\mathrm{Al}_{4} \mathrm{SiC}_{4}$ were demonstrated to exhibit crack healing upon annealing at $1300{ }^{\circ} \mathrm{C}$ in air atmosphere by forming an aluminosilicate glass which effectively filled the crack space and gave rise for an unusual strength optimum $50 \%$ higher than at room temperature [81].

The oxidation mechanism exhibits higher healing efficiency than the diffusion mechanism. When the volume of oxide exceeds the volume of the pristine material volume expansion induced by defect surface oxidation can effectively fill the defect [82] (Fig. 5). For the case that the volume increase is compensated by linear expansion perpendicular to the crack surface only, e.g., lateral expansion is restricted, the maximum crack opening $d_{\mathrm{op}}$ to be filled by the oxidation reaction product is given by

$$
d_{\mathrm{op}} \approx 2 d_{\mathrm{O}} \phi
$$

$d_{\mathrm{O}}$ is the penetration depth of the oxidant perpendicular to the surface governed by the oxidant diffusion perpendicular to the materials surface. $\phi$ is a volume expansion factor expressed by

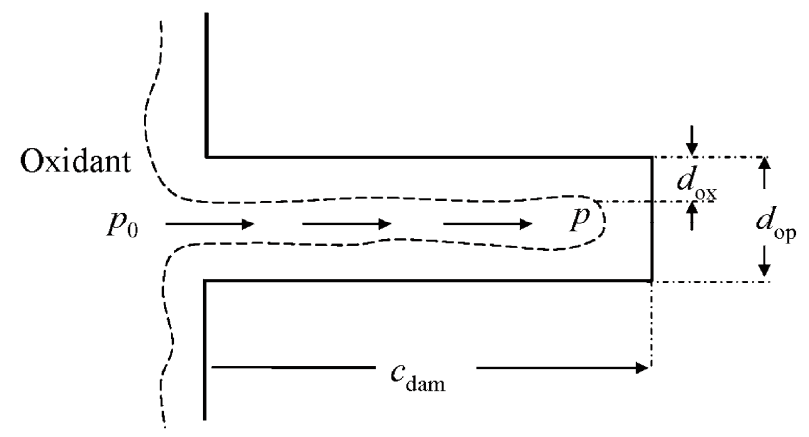

(a) Oxidation and vapour diffusion

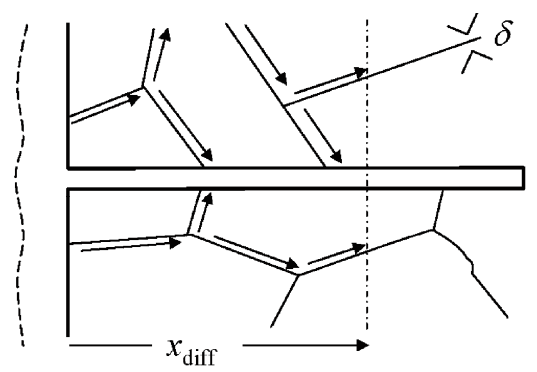

(b) Oxidation and grain boundary diffusion

Fig. 5 Oxidation reaction induced crack healing: (a) vapour transport and (b) grain boundary transport of oxidant to the crack surface.

$$
\phi=\frac{\Delta V}{V_{\mathrm{s}}^{0}}=\frac{V_{\mathrm{s}}^{\mathrm{ir}}}{V_{\mathrm{s}}^{0}}-1
$$

where $V_{\mathrm{s}}^{0}$ is the initial solid volume and $V_{\mathrm{s}}^{\text {ir }}$ is the volume of the interface reaction product (for example $\left.\mathrm{SiO}_{2}, \mathrm{TiO}_{2}, \mathrm{Al}_{2} \mathrm{O}_{3}\right)$. The volume expansion factor varies in the range from $\phi=0.54\left(\mathrm{Ti}_{2} \mathrm{AlC}\right)$ to $0.84-1.07$ for $\mathrm{Si}$ and Si-containing ceramic particles $\left(\mathrm{SiC}, \mathrm{Si}_{3} \mathrm{~N}_{4}\right)$ and attains values of $\phi>1.2$ for binary inter-metallics $\left(\mathrm{CrSi}_{2}, \mathrm{TiSi}_{2}\right)$ (Table 1). To overcome mismatch between crack volume and the amount of healing agent two approaches were proposed [51]: (i) use of elongated healing agents such as whiskers and fibers and (ii) reduction of crack opening by prestressing. Elongated healing agents would be more efficient than spherical shaped agents because of significantly lager production of reaction phase volume. The other approach is closing the crack by using phase transformation including shape memory effect (martensitic tet $\rightarrow$ mcl phase transformation in $\mathrm{ZrO}_{2}$ ) as demonstrated with polymer [83] and metal healing agents [84].

While vacancy diffusion from the crack site to the external surface characterizes solid state crack healing reaction (similar to sintering), vapour or solid transport of environmental oxidant $\left(\mathrm{O}_{2}, \mathrm{~N}_{2}\right)$ from the surface to the crack site and a reaction forming a crack filling oxide phase is required to achieve oxidation induced crack healing. Crack regression rate thus depends on the local concentration of reactant $(a)$ resulting in a modified expression

$$
-\frac{\partial c}{\partial t}=k(T) f(a)
$$

where $k(T)$ is the rate constant depending on the rate controlling reaction mechanism (e.g., transport or interface controlled). Crack healing reactions involving

Table 1 Volume expansion factors of repair fillers which undergo oxidation reaction

\begin{tabular}{cc}
\hline Oxidation reaction & $\begin{array}{c}\text { Volume } \\
\text { expansion } \\
\text { factor } \phi\end{array}$ \\
\hline $2 \mathrm{Ti}_{2} \mathrm{AlC}^{2}+13 / 2 \mathrm{O}_{2} \rightarrow 4 \mathrm{TiO}_{2}+\mathrm{Al}_{2} \mathrm{O}_{3}+2 \mathrm{CO}$ & 0.54 \\
$\mathrm{Si}_{3} \mathrm{~N}_{4}+3 \mathrm{O}_{2} \rightarrow 3 \mathrm{SiO}_{2}+2 \mathrm{~N}_{2}$ & 0.84 \\
$\mathrm{SiC}+3 / 2 \mathrm{O}_{2} \rightarrow \mathrm{SiO}_{2}+\mathrm{CO}$ & 1.00 \\
$\mathrm{Si}+\mathrm{O}_{2} \rightarrow \mathrm{SiO}_{2}$ & 1.07 \\
$2 \mathrm{CrSi}{ }_{2}+11 / 2 \mathrm{O}_{2} \rightarrow \mathrm{Cr}_{2} \mathrm{O}_{3}+4 \mathrm{SiO}_{2}$ & 1.20 \\
$\mathrm{TiSi}_{2}+3 \mathrm{O}_{2} \rightarrow \mathrm{TiO}_{2}+2 \mathrm{SiO}_{2}$ & 1.67 \\
\hline
\end{tabular}

Vitreous $\mathrm{SiO}_{2}$ density $2.2-2.6 \mathrm{~g} / \mathrm{cm}^{3}$ 
external (environment gas atmosphere) or internal (repair fillers) reactants may be represented by simple polynomial fitting to experimental $f(a)$ data or by a logical model in accordance with the suggested reaction mechanism [85]. Experimentally an expression was derived for crack healing governed by oxidation reaction of $\mathrm{SiC}$ containing ceramics [39]

$$
f(a) \approx\left(\frac{P_{\mathrm{O} 2}}{P_{\mathrm{O} 2}^{0}}\right)^{n}
$$

where $P_{\mathrm{O} 2}$ is the reduced oxygen pressure in the crack opening (compared to standard pressure of oxygen in the atmosphere $\left.P_{\mathrm{O} 2}^{0} \quad(0.02 \mathrm{MPa})\right)$. The pressuredependent constant $n$ was found to equal 0.835 and is determined by the mechanism of the rate controlling step, crack geometry and other terms. Crack-healing behaviour of $\mathrm{Al}_{2} \mathrm{O}_{3} / \mathrm{SiC}$ composites under a combustion gas atmosphere with a low oxygen partial pressure, $P_{\mathrm{O} 2}$, at temperatures of $1000-1500{ }^{\circ} \mathrm{C}$ was achieved in atmospheres with $P_{\mathrm{O} 2}>50 \mathrm{~Pa}$ (threshold of transition from active-to-passive oxidation of $\mathrm{SiC}$ ). Increasing partial pressure of $\mathrm{O}_{2}$ triggers accelerated filling of open cracks with $\mathrm{SiO}_{2}$-based reaction product. Since the reaction product phases may differ in Young's modulus and the coefficient of thermal expansion from the initial phase composition in the interface bonding area, residual stresses may form upon temperature change (cooling) which may interfere with external loading stress of the component. Thus, reaction conditions have to be selected carefully in order to minimize unfavourable residual stress formation.

\section{Microstructure modifications for accelerating crack healing}

Rough guidelines for acceleration of crack healing reaction may be derived from crack healing kinetics as expressed by the relations derived for pore perturbation and sintering and for an environmental oxidation reaction. Microstructure modifications should envisage grain boundaries with enhanced diffusivity, reduction of grain size (e.g., nanoscale powders with high surface energy), and dispersion of repair fillers that are able to stimulate healing reaction at lower activation energy (chemical (catalysis) or mechanical activation (e.g., accumulated lattice strain energy)) (Fig. 6).

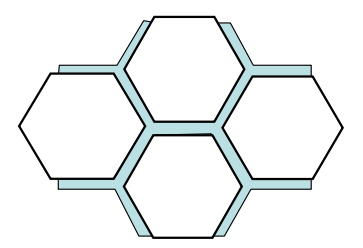

Sintering of intergranular crack via low viscous amorphous gb

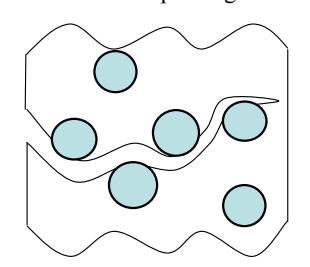

Vapor phase oxidation of repair fillers in surface flaws

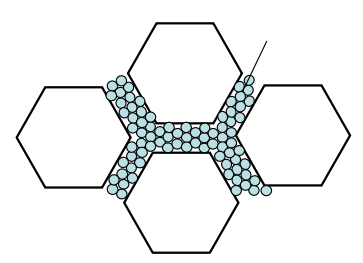

Sintering of intergranular crack in nanoscale gb microstructure

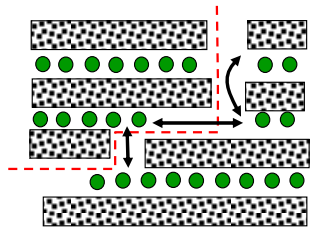

Release of weakly bonded metal from nanolaminate MAX phase
Fig. 6 Microstructures providing enhancement of material transport and repair filler reactivity.

\subsection{Enhanced material transport}

Enhanced material transport is relevant for most healing reactions when the crack regression rate $-\partial c / \partial t$ is transport controlled (Eq. (6)). The effective width of diffusion path $\delta$ was assumed to equal approximately two times the burgers vector in crystalline grain boundaries [86] and the thickness of an amorphous film wetting the grain boundaries in many liquid phase sintered ceramics [87]. Though variation of amorphous grain boundary film thickness $\delta$ is limited due to thermodynamic constraints which predict an equilibrium thickness in the range of $\delta=1-10 \mathrm{~nm}$ to exist [88], it is reasonable to suppose that the effective $\delta$ of grain boundaries wetted by an amorphous film should always be larger than for crystalline grain boundaries. Nevertheless, segregation of doping or impurity elements in crystalline grain boundaries may reduce healing temperature by increasing the grain boundary diffusivity $D_{\mathrm{gb}} \delta$. For example, $\mathrm{Y}^{3+}$ was shown to segregate at the interfaces in $\mathrm{Al}_{2} \mathrm{O}_{3}$ and form ordered structures, which may decrease diffusion coefficients [89]. Grain boundary diffusivity in $\mathrm{ZrO}_{2}$ was found to increase by doping with aliovalent elements of small atomic radius $\left(\mathrm{Ca}^{2+} \rightarrow \mathrm{In}^{3+} \rightarrow \mathrm{Nb}^{5+}\right.$, $\mathrm{Ta}^{5+}$ ) [90]. $\mathrm{ZrO}_{2} / \mathrm{SiC}$ composites where the grain size of $\mathrm{Y}^{3+}$-stabilized tetragonal $\mathrm{ZrO}_{2}$ was very small $(d \approx 0.2-0.3 \mu \mathrm{m})$ were reported to exhibit high crack healing ability in air atmosphere at temperatures as low as $600-800{ }^{\circ} \mathrm{C}$ [34].

If the grain boundary is wetted with an intergranular amorphous film, crack healing may be accelerated 
either by enhanced diffusion of oxygen along the grain boundaries or viscous flow of the vitreous phase. Liquid phase sintered $\mathrm{Si}_{3} \mathrm{~N}_{4}$ and $\mathrm{SiC}$-composites containing an amorphous grain boundary phase feature a significant crack healing at $1000{ }^{\circ} \mathrm{C}$ (also under cyclic stress), which leads to a distinct increase of the static and the dynamic fatigue strength [72]. In order to accelerate grain boundary material transport along grain boundaries wetted by an amorphous film a high value of $D_{\mathrm{gb}}$ and hence a low value of the viscosity $\eta$ should be favourable which requires modification of the composition and structure of the amorphous phase. For glasses dominated by $\mathrm{SiO}_{4}$ tetrahedra network, e.g., silica, silicate and alumina-silicate glasses, the viscosity $\eta$ was shown to be intimately connected to the structure and topology of the disordered $\mathrm{SiO}_{4}$ tetrahedra network (fragility) [91]. At temperatures near $T_{\mathrm{g}}$ (the temperature defined where $\eta=10^{13.5} \mathrm{~Pa} \cdot \mathrm{s}$, equivalent to the calorimetrically measured $T_{\mathrm{g}}$ values for oxide glasses [92]), $\eta$ was expressed as a function of glass transition temperature $T_{\mathrm{g}}$ by [58]

$$
\eta\left(T_{g}\right) \propto T_{g} \exp \left(\frac{q T_{g}}{R T}\right)
$$

where $q$ is a constant dependent on glass composition and $\left(q T_{\mathrm{g}}\right)$ equals the activation energy for viscous flow $(q \approx 260$ for silicate glasses [58]). Since maximum healing rates were reported at a temperature coinciding with the glass transformation temperature $T_{\mathrm{g}}$ [93] reduction of $T_{\mathrm{g}}$ by variation of grain boundary phase composition is of interest. For example, linear dependencies were reported for alkali-silicate and alkali-alumo-silicate glass compositions $\left(T_{\mathrm{g}}(x)[\mathrm{K}]=\right.$ 895-626x for $\left(\mathrm{Na}_{2} \mathrm{O}\right)_{x}\left(\mathrm{SiO}_{2}\right)_{1-x}$ and $T_{\mathrm{g}}(x)=1080-$ $626 x$ for $\left(\mathrm{Na}_{2} \mathrm{O}+\mathrm{MgO}\right)_{x}\left(\mathrm{Al}_{2} \mathrm{O}_{3}+\mathrm{SiO}_{2}\right)_{1-x}$ for $x=$ 0.01-0.6 [58]) as well as oxintride glasses $\left(T_{\mathrm{g}}(x)\left[{ }^{\circ} \mathrm{C}\right]=\right.$ $839+15.3 x\left(\mathrm{~mol}_{0} \mathrm{Si}_{3} \mathrm{~N}_{4}\right)$ in $\mathrm{Y}-\mathrm{Mg}-\mathrm{Si}-\mathrm{Al}-0-\mathrm{N}$ glasses [94]. Table 2 presents $T_{\mathrm{g}}$ data of selected silicate and oxinitride based glass forming systems relevant for sintering of a variety of engineering ceramics.

Earth alkaline-alumo-silicate glasses represent typical composition of intergranular glass oberseved in some oxide ceramics including alumina and zirconia as well as non-oxides such as liquid phase sintered $\mathrm{SiC}$ [101]. Oxinitride glasses present in the grain boundaries of nitride engineering ceramics $\left(\mathrm{Si}_{3} \mathrm{~N}_{4}, \mathrm{AlN}\right)$ originate from sintering additives primarily in the system $\mathrm{RE}_{2} \mathrm{O}_{3}-\mathrm{SiO}_{2}(\mathrm{RE}=$ rare earth element $\mathrm{Er}, \mathrm{Lu}$, $\mathrm{Gd}, \mathrm{Y}, \mathrm{Yb}, \mathrm{Nd}, \mathrm{Sm}, \mathrm{La}, \mathrm{Eu}$ ) with additions of alumina or earth alkaline oxides. Depending on the radius of rare earth element and the nitrogen content (nitrogen increases the network density since it connects three

Table 2 Glass transformation temperatures of silicate and oxinitride glass phases observed as grain boundary phases in ceramics

\begin{tabular}{|c|c|c|c|c|c|c|}
\hline \multirow{2}{*}{ Cation } & \multirow{2}{*}{$r_{\mathrm{c}}(\mathrm{pm})$} & \multicolumn{2}{|c|}{ Silicate glasses } & \multicolumn{3}{|c|}{ Oxynitride glasses } \\
\hline & & $T_{\mathrm{g}}\left({ }^{\circ} \mathrm{C}\right)$ & Ref. & $C_{\mathrm{N}}(\mathrm{equ} \%)$ & $T_{\mathrm{g}}\left({ }^{\circ} \mathrm{C}\right)$ & Ref. \\
\hline \multicolumn{4}{|c|}{ M-Si-Al-O (M = rare earth) } & \multicolumn{3}{|l|}{ M-Si-Al-O-N } \\
\hline $\mathrm{Lu}^{3+}$ & 86 & 910 & [67] & 22 & 1000 & {$[99]$} \\
\hline $\mathrm{Gd}^{3+}$ & 94 & 880 & {$[67]$} & 30 & 980 & {$[67]$} \\
\hline $\mathrm{Y}^{3+}$ & 90 & 920 & {$[95]$} & 18 & 1000 & {$[95]$} \\
\hline $\mathrm{Nd}^{2+}$ & $129^{*}$ & 910 & {$[95]$} & 20 & 970 & {$[95]$} \\
\hline $\mathrm{La}^{3+}$ & 103 & 850 & {$[59]$} & 29 & 940 & {$[67]$} \\
\hline $\mathrm{Eu}^{3+}$ & 95 & & & 17 & 780 & [100] \\
\hline \multicolumn{4}{|c|}{ M-Si-Al-O (M = earth alkaline, alkaline) } & \multicolumn{3}{|l|}{ M-Si-Al-O-N } \\
\hline $\mathrm{Ba}^{2+}$ & 136 & 910 & {$[96]$} & 11 & 985 & {$[96]$} \\
\hline $\mathrm{Ca}^{2+}$ & 100 & 820 & {$[95]$} & 18 & 880 & {$[95]$} \\
\hline $\mathrm{Mg}^{2+}$ & 72 & 800 & {$[95]$} & 18 & 860 & {$[94]$} \\
\hline $\mathrm{Li}^{+}$ & 76 & 485 & {$[97]$} & 2.2 (at. $\%$ ) & 520 & {$[07]$} \\
\hline \multicolumn{4}{|c|}{ M-Si-Mg-O $(\mathrm{M}=$ rare earth $)$} & \multicolumn{3}{|l|}{ M-Si-Mg-O-N } \\
\hline $\mathrm{Lu}^{3+}$ & 86 & 800 & {$[98]$} & 20 & 890 & {$[98]$} \\
\hline $\mathrm{La}^{3+}$ & 103 & 780 & {$[98]$} & 20 & 850 & [98] \\
\hline
\end{tabular}

$r_{\mathrm{c}}$ is given for coordination number 6 except $*$ for coordination number 8 ; $C_{\mathrm{N}}$ : nitrogen content. 
Si-tetrahedra instead of two of oxygen) the glass properties may vary in a wide range with glass transition temperature $T_{\mathrm{g}}$ decreasing from approximately $1000{ }^{\circ} \mathrm{C}$ for $\mathrm{Lu}^{3+}\left(r_{[6]}=89 \mathrm{pm}\right)$ to $<800{ }^{\circ} \mathrm{C}$ for $\mathrm{Eu}^{2+}\left(r_{[6]}=117 \mathrm{pm}\right)$ at nitrogen contents of approximately 20 equ\%. Nitrogen solubilities are sensitive to the oxynitride glass composition and become smaller as the $\mathrm{RE}_{2} \mathrm{O}_{3} / \mathrm{SiO}_{2}$ ratio is reduced and as the $\mathrm{RE}$ size decreases from $\mathrm{La}^{3+}>\mathrm{Nd}^{3+}>$ $\mathrm{Sm}^{3+}>\mathrm{Gd}^{3+}>\mathrm{Y}^{3+}>\mathrm{Yb}^{3+}, \mathrm{Lu}^{3+}>\mathrm{Sc}^{3+}$ [59]. Oxidation of the intergranular oxinitride phase causes the $\mathrm{N}: \mathrm{O}$ ratio to minimize resulting in a shift of $T_{\mathrm{g}}$ to temperatures approximately $60-100{ }^{\circ} \mathrm{C}$ lower in the nitrogen free systems [102].

Grain size reduction not only gives rise for an accelerated diffusive (and viscous) flow along grain boundaries (second stage of crack healing) but may also facilitate perturbation of a crack-like pore (initial stage). According to the analyses of Nichols and Mullins [103] and Stüwe and Kolednik [104], the time for surface-diffusion controlled disintegration $t_{\text {dis }}$ for a semi-infinite cylinder pore of radius $r_{0}$ was approximated by Gupta [52]

$$
t_{\text {dis }} \approx 0.584 \frac{k_{\mathrm{B}} T r_{0}^{4}}{D_{0, \mathrm{~s}} \gamma_{\mathrm{s}} \Omega^{2} v} \exp \left(\frac{\Delta G_{\mathrm{s}}^{*}}{k_{\mathrm{B}} T}\right)
$$

For an intergranular crack propagating along the grain boundaries it may be reasonable to correlate the perturbation wave length $\lambda$ with the grain size $d$ and perturbation amplitude $a_{0}$ with the crack opening $r_{0}$ which in a cohesive zone might attain a maximum value of $r_{0} \leqslant d / 4 \quad$ (Fig. 7). Taking $\Omega=2.11 \times$ $10^{-23} \mathrm{~cm}^{3} /$ at,$v=1.31 \times 10^{15} \mathrm{at} / \mathrm{cm}^{2} \quad$ [52], $k_{\mathrm{B}}=1.380 \times$ $10^{-23} \mathrm{~J} / \mathrm{K}$, the temperature variation of particle size $d(T)$ able to initiate Rayleigh instability of a crack-like pore was estimated for a constant time of disintegration of $t_{\mathrm{dis}}=1 \mathrm{~h}$ from

$$
d(T) \approx 0.508\left[\frac{D_{0, \mathrm{~s}} \gamma_{\mathrm{s}}}{T} \exp \left(-\frac{\Delta G_{\mathrm{s}}^{*}}{k_{\mathrm{B}} T}\right)\right]^{\frac{1}{4}}
$$

Values of $D_{0, \mathrm{~s}}, \gamma_{\mathrm{s}}$ and $\Delta G_{\mathrm{s}}^{*}$ of various ceramics are given in Table 3.

Despite of the rough approximation and the uncertainty in the diffusion values, it may be seen from Fig. 7 that most of the ceramics displayed may initiate surface diffusion controlled ovulation of crack like pores at grain sizes smaller than 100-10 nm (except $\mathrm{WC}$ and Si). Processing of defect free sintered ceramics with such small grain size, however, is a great challenge since uncontrolled agglomeration during shaping and exaggerated grain growth during sintering may cause severe limitations to the mechanical as well as functional properties [116]. Duplex type ceramics [117] with a nanoscale microstructure in the grain boundaries of micro-scale matrix grains as sketched in Fig. 6 may offer the potential of better control of grain growth resulting in ceramics with improving crack healing behaviour.

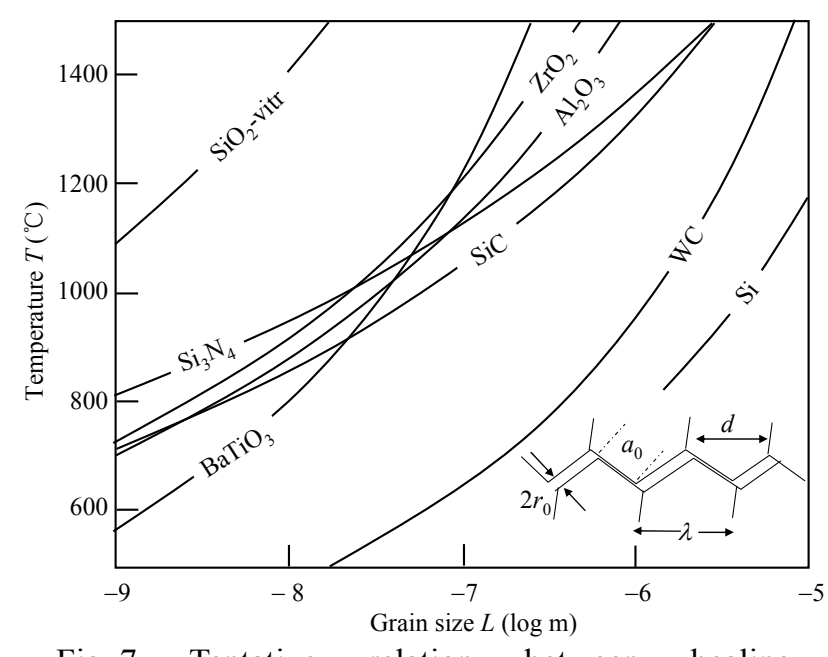

Fig. 7 Tentative relation between healing temperature and particle size calculated for surface diffusion controlled pore perturbation (initial stage).

Table 3 Surface diffusion data of selected ceramics

\begin{tabular}{ccccccc}
\hline Ceramic & $D_{0, \mathrm{~s}}\left(\mathrm{~cm}^{2} / \mathrm{s}\right)$ & $\Delta G_{\mathrm{s}}^{*}(\mathrm{~kJ} / \mathrm{mol})$ & $T\left({ }^{\circ} \mathrm{C}\right)$ & Ref. & $\gamma_{\mathrm{s}}\left(\mathrm{J} / \mathrm{m}^{2}\right)$ & Ref. \\
\hline $\mathrm{Al}_{2} \mathrm{O}_{3}$ & $4.2 \times 10^{6}$ & 494 & $1400-1800$ & {$[52]$} & 0.905 & {$[52]$} \\
$\mathrm{ZrO}_{2}(\mathrm{Y}-\mathrm{TZP})$ & $1.2 \times 10^{5}$ & 478 & 1000 & {$[105]$} & 1.63 & {$[111]$} \\
$\mathrm{BaTiO}_{3}$ & $1 \times 10^{-1}$ & 307 & $1100-1200$ & {$[106]$} & & \\
$\mathrm{SiO}_{2}$-vitreous & $6.5 \times 10^{2}$ & 572 & $1200-1580$ & {$[107]$} & 0.29 & {$[112]$} \\
$\mathrm{Si}$ & $9.4 \times 10^{6}$ & 298 & $1200-1400$ & {$[108]$} & 1.05 & {$[113]$} \\
$\mathrm{Si}_{3} \mathrm{~N}_{4}$ & $1.9 \times 10^{16}$ & 757 & $<1500$ & {$[108]$} & 1.95 & {$[114]$} \\
$\mathrm{SiC}$ & $4 \times 10^{11}$ & 600 & $1400-2200$ & {$[109]$} & 2.2 & {$[115]$} \\
$\mathrm{WC}$ & $1.6 \times 10^{4}$ & 298 & $950-1200$ & {$[110]$} & 2.45 & {$[110]$} \\
\hline
\end{tabular}




\subsection{Enhanced reactivity of repair fillers}

Incorporation of repair fillers able to release a healing agent upon crack opening is a current approach for crack repair in thermoset polymer materials [7,11]. Repair fillers dispersed in a ceramic matrix may trigger crack healing when an oxidant is transported from the environmental atmosphere to the repair filler exposed to the crack surface. Though only few repair fillers reacting with oxygen are given in Table 1, a large number of elements and compounds are suitable candidates for fillers reacting with oxygen as well as other gases (e.g., nitrogen, hydrocarbons, etc.). If the healing reaction kinetics is governed by transport of the oxidant to the reaction site at the crack surface, recovery kinetics are expected to follow the relations presented above. However, if transport of the oxidant via gas phase or interface flow or diffusion is fast enough, interface reaction of the repair filler will be rate controlling for the crack healing reaction.

Arrhenius law predicts that the rate constant $k(T)=$ $A \exp \left[-\Delta G^{*} /\left(k_{\mathrm{B}} T\right)\right]$ in Eq. (14) will be governed by the activation energy barrier $\Delta G^{*}$. Following thermodynamic arguments for solid state reaction kinetics, chemical or mechanical activation of the repair filler equals to an increase of Gibbs free energy, $\Delta G_{\text {act }}$, which gives rise to a reduction of the activation energy barrier, $\left(\Delta G^{*}-\Delta G_{\text {act }}\right)$. It is evident that a reduction of activation energy barrier corresponds to an equivalent decrease of reaction temperature $T_{\text {act }}$

$$
\frac{T_{\text {act }}}{T} \propto\left(1-\Delta G_{\text {act }}\right)
$$

Independent on the specific rate controlling reaction process, this simple scaling law suggests that we may expect lower crack healing temperatures by appropriate modification of the repair filler. Table 4 summarizes scaling relations for $\Delta G_{\text {act }}$ in dependence on surface energy and strain energy accumulation.

Driven by an excess of surface energy nanoparticles were shown to exhibit a pronounced reduction of phase transformation temperatures such as melting, evaporation and viscous flow [118-120]. Accumulation of mechanical strain $\varepsilon$ by extended milling (mechanical activation) may cause a pronounced increase of dislocation concentration [121]. Dislocation densities ranging from $10^{14}$ to $10^{18} \mathrm{~m}^{-2}$ were reported for a variety of milled inorganic powders which give rise to stored energy increase corresponding to $\Delta G_{\text {act }} \sim$ $0.1-100 \mathrm{~kJ} / \mathrm{mol}$ [122]. Moreover, as a result of lattice defect accumulation driving forces for solid-state and chemical reactions increase and solid state diffusion is accelerated at low temperatures [123]. Similar thermodynamic considerations describe the size effect on the reduction of melting temperature of nanoscale particles [124], disorder-induced amorphization [125], and disorder induced melting of amorphous solids [126].

Experimental observation revealed significantly higher oxidation reaction rates when the particle size of the $\mathrm{SiC}$ repair filler dispersed in an $\mathrm{Al}_{2} \mathrm{O}_{3}$ matrix was reduced to nanoscale [51]. Thus, apparent activation energies derived from DTA measurements of peak temperature for oxidation reaction, $T_{\mathrm{p}}$, at constant heating rates revealed a pronounced decrease with particle size from $\Delta G^{*}=383 \mathrm{~kJ} / \mathrm{mol}$ at $d=270 \mathrm{~nm}$ to $268 \mathrm{~kJ} / \mathrm{mol}$ at $30 \mathrm{~nm}$ to $197 \mathrm{~kJ} / \mathrm{mol}$ at $10 \mathrm{~nm}$,

Table 4 Gibbs energy scaling laws for solid state activated processes

\begin{tabular}{lcc}
\hline \multicolumn{1}{c}{ Activation process } & Gibbs energy increase $\Delta G_{\text {act }}$ & Ref. \\
\hline Surface energy accumulation & $\propto \frac{\gamma V_{\mathrm{mol}}}{\Delta H_{\mathrm{tr}} d}$ & {$[118]$} \\
Reduction of melting temperature & $\propto \frac{\gamma_{\mathrm{s}} \Omega}{E_{\mathrm{c}} d}$ & \\
Reduction of evaporation temperature & $\propto \frac{d_{\min }}{d}$ & {$[119]$} \\
Reduction of viscous flow temperature & $\propto \frac{V_{\mathrm{mol}} \varepsilon_{0}\left\langle\varepsilon^{2}\right\rangle^{1 / 2}}{\Delta H_{\mathrm{tr}} d b}$ & \\
Strain energy accumulation & $1121]$ \\
Reduction of reaction temperature &
\end{tabular}

$\gamma_{\mathrm{s}}:$ the surface energy; $V_{\mathrm{mol}}:$ molecular volume; $\Delta H_{\mathrm{tr}}:$ transformation enthalpy; $d$ : particle size; $E_{\mathrm{c}}:$ bulk cohesive energy per atom; $\Omega$ : atom volume; $\varepsilon$ : accumulated strain by mechanical milling; $\varepsilon_{0}$ : overall strain energy per unit length of dislocation; $b$ : burgers vector. 
respectively. However, alumina composite containing $\mathrm{SiC}$ particles whose particle size is less than $10 \mathrm{~nm}$ cannot recover completely the cracked strength under every condition, because the space between crack walls cannot be filled with the formed oxide due to the small volume of $\mathrm{SiC}$ on the crack walls. Therefore, an optimal SiC particle size for endowing self-healing ability was postulated to exist. Nano-metal particles containing ceramic matrix composites offer promising potential for oxidation induced crack healing at temperatures significantly lower than $1000{ }^{\circ} \mathrm{C}$. Nano-Mo/ $/ \mathrm{Al}_{2} \mathrm{O}_{3}$ hybrid materials have the crack-healing function by thermal oxidation process as low as $700{ }^{\circ} \mathrm{C}$ [127].

For the oxidation of MAX phases, weak bonding between $\mathrm{M}-\mathrm{A}$ and preferred oxidation of $\mathrm{A}$ is the main mechanism. The formation temperature of $\mathrm{A}$ containing oxides was found to depend on the bonding strength and stability of MAX phases. While oxidation temperatures of $1100-1200{ }^{\circ} \mathrm{C}$ were reported for preferred oxidation of $\mathrm{Al}$ forming hard, strong and protective $\mathrm{Al}_{2} \mathrm{O}_{3}$ layer on $\mathrm{Ti}_{3} \mathrm{AlC}_{2}$ and $\mathrm{Ti}_{2} \mathrm{AlC}$ [68,80,128-130] lower oxidation temperatures $<$ $1000{ }^{\circ} \mathrm{C}$ might be expected by substituting with an A-element of lower bonding energy than $\mathrm{Al} . \mathrm{M}_{n+1} \mathrm{AX}_{n}$ phases with $A$ being a low melting metal $(A=\mathrm{Ga}$, In) were recently reported to exhibit unusual physical phenomena based on deintercalation of the A element [131]. Though the driving force for the deintercalation of the A metal from the basal (0001) planes of $\mathrm{M}_{2} \mathrm{AC}$ is still discussed controversly, the high mobility of the intercalating low melting metal indicates a low cohesive bonding energy $E_{\mathrm{B}}$ as well as migration energy $E_{\mathrm{m}}$ of the A metal layer as confirmed by $a b$ initio calculations [132]. Thus, MAX phase based composite materials with low melting metals like Sn, $\mathrm{In}$, or $\mathrm{Pb}$ on the A position might be of great interest to serve as repair filler requiring significantly lower healing temperatures to trigger oxidation healing reaction compared to common engineering ceramic materials. For example, substitution of A element $\mathrm{Al}$ (cohesive energy $E_{\mathrm{c}} \approx 10.4 \mathrm{eV}$ and migration energy $\left.(0001) \quad E_{\mathrm{m}} \approx 0.82 \mathrm{eV}\right)$ by $\mathrm{Sn} \quad\left(E_{\mathrm{B}} \approx 8.1 \mathrm{eV}\right.$ and $E_{\mathrm{m}} \approx 0.66 \mathrm{eV}$ ) [132] in $\mathrm{Ti}_{2} \mathrm{AC}$ was shown to decrease the temperature for A-element oxidation

$$
\begin{array}{ll}
2 \mathrm{Al}+3 / 2 \mathrm{O}_{2} \rightarrow \mathrm{Al}_{2} \mathrm{O}_{3}, & \Delta G_{740} \mathrm{c}=-1356 \mathrm{~kJ} / \mathrm{mol} \\
\mathrm{Sn}+\mathrm{O}_{2} \rightarrow \mathrm{SnO}_{2}, & \Delta G_{500 \mathrm{c}}=-415 \mathrm{~kJ} / \mathrm{mol}
\end{array}
$$

Measured by DTA and XRD from approximately

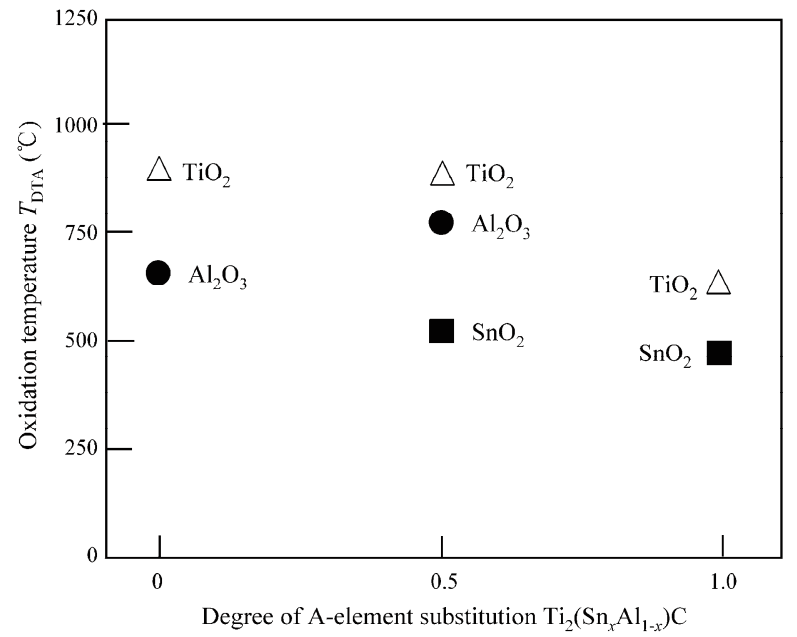

Fig. 8 Reduction of oxidation temperature for $\mathrm{M}$ and $\mathrm{A}$ elements of $\mathrm{M}_{2} \mathrm{AC}$ phase with $\mathrm{M}=\mathrm{Ti}$ and $\mathrm{A}=$ $\mathrm{Al}$ and Sn (courtesy J. Pedimonte and G. P. Bei, University of Erlangen 2012).

$740{ }^{\circ} \mathrm{C}$ to $500{ }^{\circ} \mathrm{C}$ (Fig. 8). At these temperatures crack filling with the oxide reaction products was observed by SEM, whereas oxidation of Ti requires significantly higher temperatures. Though a lower cohesive energy corresponds to a reduced thermal stability of the MAX phase surface coating of activated repair fillers may avoid decomposition during consolidation offering a high potential for development of repair filler loaded composite ceramics with enhanced crack healing ability at temperatures below $1000{ }^{\circ} \mathrm{C}$.

Nitridation crack healing in polymer derived SiOC ceramics recently was reported to yield improved mechanical properties of extrusion formed filler loaded polysiloxane polymer systems [133,134]. While nitridation of Si-O-C based ceramic residue requires temperatures exceeding $1200{ }^{\circ} \mathrm{C}$ significantly lower reaction temperatures below $1000{ }^{\circ} \mathrm{C}$ were observed in the presence of catalytically active metal silicide fillers $\left(\mathrm{MeSi}_{2}\right.$ with $\left.\mathrm{Me}=\mathrm{Fe}, \mathrm{Cr}, \mathrm{V}\right)$ [135]. For example, polysiloxanes filled with carbide and metal silicide fillers $(\mathrm{Fe}-\mathrm{Si}-\mathrm{Cr})$ were demonstrated to exhibit crack healing in nitrogen atmosphere by formation of metal nitride reaction products which exhibit a pronounced volume expansion effect. Simultaneously, the repair filler triggers nitridation of the $\mathrm{Si}-\mathrm{O}-\mathrm{C}$ matrix as a heterogeneous catalyst at temperatures as low as $800{ }^{\circ} \mathrm{C}$ with $\mathrm{Si}_{2} \mathrm{~N}_{2} \mathrm{O}$ and $\mathrm{Si}_{3} \mathrm{~N}_{4}$ filling the crack space

$$
\begin{array}{r}
2 \mathrm{SiO}(\mathrm{g})+\mathrm{C}(\mathrm{s})+\mathrm{N}_{2}(\mathrm{~g}) \rightarrow \mathrm{Si}_{2} \mathrm{~N}_{2} \mathrm{O}(\mathrm{s})+\mathrm{CO}(\mathrm{g}), \\
\Delta G_{800 \mathrm{c}}=-437 \mathrm{~kJ} / \mathrm{mol}
\end{array}
$$




$$
\begin{aligned}
3 \mathrm{SiO}(\mathrm{g})+3 \mathrm{C}(\mathrm{s})+2 \mathrm{~N}_{2}(\mathrm{~g}) & \rightarrow \mathrm{Si}_{3} \mathrm{~N}_{4}(\mathrm{~s})+3 \mathrm{CO}(\mathrm{g}), \\
\Delta G_{800} \mathrm{c} & =-428 \mathrm{~kJ} / \mathrm{mol}
\end{aligned}
$$

High mobility of vapour phase reactants $\mathrm{SiO}(\mathrm{g})$ and $\mathrm{N}_{2}$ (g) facilitates long range transport and nitride and oxinitride reaction products may fill open pores and cracks (Fig. 9). Compared to the low level of fracture toughness of 1-2 MPa. $\mathrm{m}^{1 / 2}$ associated with the porous and amorphous microstructure of the polymer derived ceramic residue [136], formation of dense crystalline oxinitride/nitride surface layers may attain significantly higher toughness ranging from $3\left(\mathrm{Si}_{2} \mathrm{~N}_{2} \mathrm{O}\right)$ to $>6 \mathrm{MPa} \cdot \mathrm{m}^{1 / 2}\left(\mathrm{Si}_{3} \mathrm{~N}_{4}\right)[137,138]$.

Moreover, the catalytic fillers dispersed in the Si-O-C may undergo nitridation reaction, as for example,

$$
\begin{gathered}
3 \mathrm{CrSi}_{2}+\frac{11}{2} \mathrm{~N}_{2} \rightarrow 3 \mathrm{CrN}+2 \mathrm{Si}_{3} \mathrm{~N}_{4}, \\
\Delta G_{8000^{\circ} \mathrm{C}}=-607 \mathrm{~kJ} / \mathrm{mol}
\end{gathered}
$$

which ultimately may give rise for a pronounced volume expansion factor. Figure 10 shows pore filling effect upon annealing a $\mathrm{CrSi}_{2}$-loaded Si-O-C composite in nitrogen atmosphere for a period of

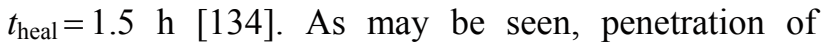
nitrogen causes effective reduction of porosity at least near the surface which gave rise for a pronounced improvement of fracture strength $\left(\sigma_{\text {heal }} / \sigma_{0}\right) \approx 1.5$. Since surface nitridation treatment may effectively trigger healing of open cracks without forming low viscous
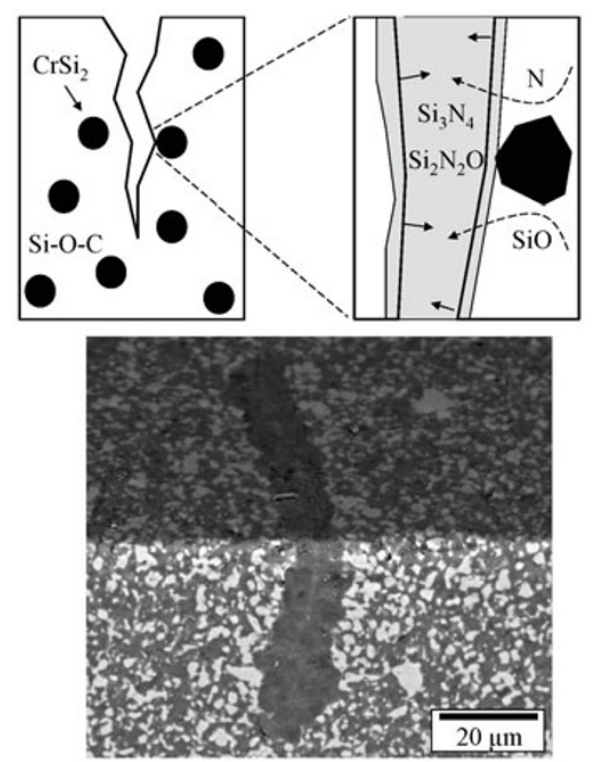

Fig. 9 Scheme of repair filler catalyzed nitrididation crack healing in polymer-derived Si-O-C ceramic. oxide products (silica and silicates), we can expect improved wear stability at elevated temperatures.

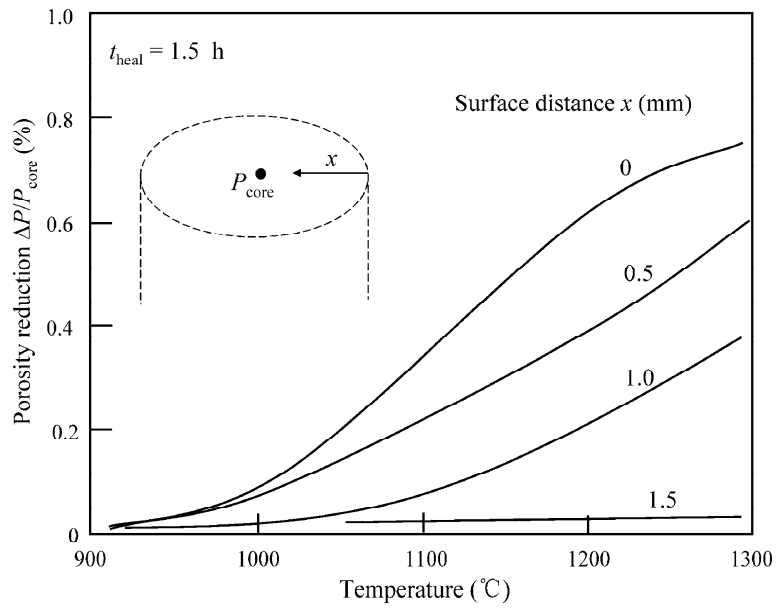

Fig. 10 Effect of healing temperature on porosity reduction of $\mathrm{CrSi}_{2}$ loaded $\mathrm{Si}-\mathrm{O}-\mathrm{C}$ ceramic composite annealed in nitrogen atmosphere.

Though oxidation induced healing reactions may facilitate partial of complete refilling of the open crack space and restore solid state bonding between crack wakes, the properties of the filled crack may differ from the virgin matrix material. Different phases as for example amorphous $\mathrm{SiO}_{2}$ filling cracks and voids in Si-containing ceramics $\left(\mathrm{SiC}, \mathrm{Si}_{3} \mathrm{~N}_{4}\right)$ may undergo phase transitions (crystallisation, allotropic phase transition). Different thermal expansion compared to the matrix material may give rise for residual stress generation upon temperature changes. Thus, selection of repair fillers has to consider thermo-mechanical compatibility of reaction products. Furthermore, processing of highly reactive repair filler systems is a great challenge and sintering temperatures might be limited requiring novel consolidation techniques.

\section{Conclusions}

Thermodynamic and kinetic aspects governing the regeneration of solid contact able to transfer stress between disrupted crack surfaces in ceramics (crack healing) were reviewed. While previous work mainly referred to thermal treatment at temperatures exceeding $1000{ }^{\circ} \mathrm{C}$ in order to provide activation energy for solid state reactions including sintering and oxidation, current work seeks for microstructure modifications which stimulate healing reactions to 
proceed at significantly lower temperatures. Potentially useful approaches to accelerate healing reaction and reduce healing temperature (and time) in ceramics and ceramic composites envisage an enhancement of material transport and an increase of reactivity of repair fillers. It should be kept in mind, however, that despite of solid material filling of a crack space healing treatment often cannot provide a complete recovery of undamaged material.

Implementation of crack healing capability into advanced ceramics is attractive for extending load bearing applications currently limited by accumulated damage which may cause a reduction of failure stress with time. Great potentials are to be seen in reconsidering component design and extend lifetime. Furthermore, processing and inspection costs may be reduced making engineering ceramics applications more cost effective.

\section{Acknowledgement}

Financial support from DFG projects GR 961/34 and GR 961/32 (Reinhart Kosselleck) is gratefully acknowledged.

\section{References}

[1] Feng QL, Cui FZ, Pu G, et al. Crystal orientation, toughening mechanisms and a mimic of nacre. Mat Sci Eng C 2000, 11: 19-25.

[2] Vander Zwaag S. Self Healing Materials. Dordrecht: Springer, 2007.

[3] Ghosh SK. Self-Healing Materials: Fundamentals, Design Strategies, and Applications. Weinheim: Wiley-VCH, 2009.

[4] Hager MD, Greil P, Leyens C, et al. Self healing materials. Adv Mat 2010, 22: 30-36.

[5] Nosonovsky M, Rohatgi PK. Biomimetics in Materials Science, Self-Healing, Self-Lubricating, and Self Cleaning Materials. Berlin: Springer, 2012.

[6] Yasuhara H, Marone C, Elshworth D. Fault zone restrengthening and frictional healing: The role of pressure solution. $J$ Geophy Res 2005, 110: 06310.

[7] White SR, Sottos NR, Geubelle PH, et al. Autonomic healing of polymer composites. Nature 2001, 409: 794-797.

[8] Sigumonrong PD, Zhang J, Zhou Y, et al. Interfacial structure of $\mathrm{V}_{2} \mathrm{AlC}$ thin films deposited on (1120)-sapphire. Scr Mater 2011, 84: 347-350.
[9] Dementsov A, Privman V. Three-dimensional percolation modelling of self-healing composites. Phys Rev E 2011, 78: 021106.

[10] Evans AG, Charles EA. Strength recovery by diffusive crack healing. Acta Metall 1977, 25: 918-927.

[11] Wool RP. Self-healing materials: A review. Soft Matter 2008, 4: 400-418.

[12] Sottos N, White S, Bond I. Introduction: Self-healing polymers and composites. $J$ Roy Soc 2007, 4: 347-348.

[13] Jarvis EA, Carter EA. A nanoscale mechanism of fatigue in ionic solids. Nano Lett 2006, 6: 505-509.

[14] Hager HD, Greil P, Leyens C, et al. Self healing materials. Adv Mat 2010, 22: 5424-5430.

[15] Jun L, Zheng ZX, Ding HF, et al. Preliminary study of the crack healing and strength recovery of $\mathrm{Al}_{2} \mathrm{O}_{3}$-matrix composites. Fatigue \& Fract Eng Mat 2004, 27: 89-97.

[16] Nichols FA, Mullins WW. Surface-(interface) and volume-diffusion contributions to morphological changes driven by capillarity. Trans AIME 1965, 233: $1840-1848$.

[17] Yen CF, Coble RL. Spheroidization of tubular voids in $\mathrm{Al}_{2} \mathrm{O}_{3}$ crystals at high temperatures. $\mathrm{J} \mathrm{Am}$ Ceram Soc 1972, 55: 507-509.

[18] Wiederhorn SM, Townsend PR. Crack healing in glass. J Am Ceram Soc 1970, 53: 486-489.

[19] Ackler HD. Healing of lithographically introduced cracks in glass and glass-containing Ceramics. $J \mathrm{Am}$ Ceram Soc 1998, 81: 3093-3103.

[20] Wang Z, Li YZ, Harmer MP, et al. Thermal healing of laser-induced internal cracks in lithium fluoride crystals. J Am Ceram Soc 1992, 75: 1596-1602.

[21] Roberts JT, Wronda BJ. Crack healing in $\mathrm{UO}_{2} . J \mathrm{Am}$ Ceram Soc 1973, 56: 297-299.

[22] Bandyopadhyay G, Roberts JT. Crack healing and strength recovery in $\mathrm{UO}_{2} . J$ Am Ceram Soc 1976, 59: 415-419.

[23] Lange FF, Radford KC. Healing of surface cracks in polycrystalline $\mathrm{Al}_{2} \mathrm{O}_{3}$. J Am Ceram Soc 1970, 53: 420-421.

[24] Gupta TK. Crack healing in thermally shocked MgO. J Am Ceram Soc 1975, 58: 143-150.

[25] Kim YW, Ando K, Chu CM. Crack-healing behavior of liquid-phase-sintered silicon carbide ceramics. J Am Ceram Soc 2003, 86: 465-470.

[26] Lee SK, Ishida W, Lee SY, et al. Crack-healing behavior and resultant strength properties of silicon carbide ceramic. J Europ Ceram Soc 2005, 25: $569-576$. 
[27] Mitomo M, Nishimura T, Tsutsumi M. Crack healing in silicon nitride and alumina ceramics. $J$ Mat Sci Lett 1996, 15: 19-26.

[28] Yao F, Ando K, Chu MC, et al. Static and cyclic fatigue behaviour of crack healed $\mathrm{Si}_{3} \mathrm{~N}_{4} / \mathrm{SiC}$ composite ceramics. J Europ Ceram Soc 2001, 21: 991-997.

[29] Rödel J, Glaeser AM. High-temperature healing of lithographically introduced cracks in Sapphire. $J$ Am Ceram Soc 1990, 73: 592-601.

[30] Takahashi K, Yokouchi M, Lee SK, et al. Crack-healing behavior of $\mathrm{Al}_{2} \mathrm{O}_{3}$ toughened by $\mathrm{SiC}$ whiskers. J Am Ceram Soc 2003, 86: 2143-2147.

[31] Nakao W, Ono M, Lee SK, et al. Critical crack-healing condition for $\mathrm{SiC}$ whisker reinforced alumina under stress. J Europ Ceram Soc 2005, 25: 3649-3655.

[32] Chu MC, Sato S, Kobayashi Y, et al. Damage healing and strengthening behavior in intelligent mullite/SiC ceramics. Fatigue \& Fract Eng Mat 1995, 18: 1019-1029.

[33] Nakao W, Mori S, Nakamura J, et al. Selfcrack-healing behavior of mullite/SiC particle/SiC whisker multi-composites and potential use for ceramic springs. J Am Ceram Soc 2006, 89: 1352-1357.

[34] Houjou K, Ando K, Takahashi K. Crack-healing behaviour of $\mathrm{ZrO}_{2} / \mathrm{SiC}$ composite ceramics. Int $J$ Struct Integrity 2010, 1: 73-84.

[35] Chan KS, Page RA. Origin of the creep-crack growth threshold in a glass-ceramic. $J$ Am Ceram Soc 1992, 75: 603-612.

[36] Clarke DR, Lange FF. Strengthening of silicon nitride by a post-fabrication annealing. $\mathrm{J} \mathrm{Am} \mathrm{Ceram}$ Soc 1982, 65: 51-52.

[37] Nakatani M, Ando K, Houjou K. Oxidation behaviour of $\mathrm{Si}_{3} \mathrm{~N}_{4} / \mathrm{Y}_{2} \mathrm{O}_{3}$ system ceramics and effect on crack-healing treatment on oxidation. $J$ Europ Ceram Soc 2008, 28: 1251-1257.

[38] Lange FF. Healing of surface cracks in SiC by oxidation. J Am Ceram Soc 1970, 53: 290-293.

[39] Osada T, Nakao W, Takahashi K, et al. Kinetics of self-crack-healing of alumina/silicon carbide composite including oxygen partial pressure effect. J Am Ceram Soc 2009, 92: 864-870.

[40] Jung YS, Nakao W, Takahashi K, et al. Crack healing of machining cracks induced by wheel grinding and resultant high-temperature mechanical properties in a $\mathrm{Si}_{3} \mathrm{~N}_{4} / \mathrm{SiC}$ composite. $\mathrm{J} \mathrm{Am}$ Ceram Soc 2009, 92: 167-173.

[41] Harrer W, Danzer R, Morrell R. Influence of surface defects on the biaxial strength of a silicon nitride ceramic-Increase of strength by crack healing. J Europ Ceram Soc 2012, 32: 27-35.

[42] Quemard L, Rebillat F, Guette A, et al. Self-healing mechanisms of a $\mathrm{SiC}$ fiber reinforced multi-layered ceramic matrix composite in high pressure steam environments. J Europ Ceram Soc 2007, 27: 2085-2094.

[43] Boccaccini AR, Ponton CB, Chawla KK. Development and healing of matrix microcracks in fibre reinforced glass matrix composites: Assessment by internal friction. Mat Sci Eng 1998, 241: 141-150.

[44] Chu MC, Cho SJ, Yoon KJ, et al. Crack repairing in alumina by penetrating glass. J Am Ceram Soc 2005, 88: 491-493.

[45] Takahashi K, Ando K, Murase H, et al. Threshold stress for crack-healing of $\mathrm{Si}_{3} \mathrm{~N}_{4} / \mathrm{SiC}$ and resultant cyclic fatigue strength at the healing temperature. $J$ Am Ceram Soc 2005, 88: 648-651.

[46] Chan KS, Page RA. Creep development in structural ceramics. J Am Ceram Soc 1993, 76: 803-826.

[47] Rice JR. Thermodynamics of quasi-static growth of Griffith cracks. J Mech Phys Solids 1978, 26: 61-78.

[48] Lawn B. Fracture of Brittle Solids, 2nd ed. Cambridge: Cambridge University Press 1993.

[49] Lawn BR. An atomistic model of kinetic crack growth in brittle solids. J Mat Sci 1975, 10: 469-480.

[50] Brantley SL, Evans B, Hickman SH, et al. Healing of microcracks in quartz: Implica-tions for fluid flow. Geology 1990, 18: 136-139.

[51] Nakao W, Abe S. Enhancement of the self-healing ability in oxidation induced self-healing ceramic by modifying the healing agent. Smart Mat Struct 2012, 21: $25-32$.

[52] Gupta TK. Instability of cylindrical voids in alumina. J Am Ceram Soc 1978, 61: 191-195.

[53] Amamato Y, Kamada J, Otsuka H, et al. Repeatable photoinduced self-healing of covalently cross-linked polymers through reshuff-ling of trithiocarbonate units. Angew Chemie 2011, 50: 1660-1663.

[54] Gupta TK. Kinetics of strengthening of thermally shocked $\mathrm{MgO}$ and $\mathrm{Al}_{2} \mathrm{O}_{3}$. J Am Ceram Soc 1976, 59: 448-449.

[55] Wilson BA, Lee KY, Case ED. Diffusive crack-healing behavior in polycrystalline alumina: A comparison between microwave annealing and conventional annealing. Mat Res Bull 1997, 32: 1607-1616. 
[56] Stevens RN, Dutton R. The propagation of Griffith cracks at high temperatures by mass trans-port process. Mat Sci Eng 1971, 8: 220-234.

[57] Gupta TK. Crack healing in $\mathrm{Al}_{2} \mathrm{O}_{3}, \mathrm{MgO}$ and related materials. J Am Ceram Soc 1984: 750-766.

[58] Hickman SH, Evans B. Diffusional crack healing in calcite: The influence of crack geometry on healing rate. Phys Chem Min 1987, 15: 91-102.

[59] Huang P, Sun J. A numerical analysis of intergranular penny-shaped microcrack shrinkage controlled by coupled surface and interface diffusion. Met and Mat Trans 2004, 35: 1294-1301.

[60] Dutton R. Comments on "Crack healing in $\mathrm{UO}_{2}$ ". $J$ Am Ceram Soc 1973, 56: 660-661.

[61] Dutton R. The propagation of cracks by diffusion. In Fracture Mechanics of Ceramics. New York: Plenum Press, 1974: 649-657.

[62] Dutton R. Correction-comments on "Crack healing in $\mathrm{UO}_{2}$ ". J Am Ceram Soc 1976, 59: 880-881.

[63] Bandyopadhay G, Kennedy CR. Thermal crack healing and strength recovery in $\mathrm{UO}_{2}$ subjected to varying degrees of thermal shock. J Am Ceram Soc 1977, 60: 48-50.

[64] Dryden JR, Kucerovsky D, Wilkinson DS, et al. Creep deformation due to a viscous grain boundary phase. Acta Metall 1989, 37: 2007-2015.

[65] Ferreira Nascimento ML, Zanotto ED. Diffusion processes in vitreous silica revisited. Phys Chem Glasses: Eur J Glass Sci Technol 2007, 48: 201-217.

[66] Avramov I, Vassilev TS, Penkov I. The glass transition temperature of silicate and borate glasses. J Non-Crystalline Sol 2005, 351: 472-476.

[67] Becher PF, Hampshire S, Pomeroy MJ, et al. An overview of the structure and properties of silicon-based oxynitride glasses. J Appl Glass Sci 2011, 2: 63-83.

[68] Song GM, Pei YT, Sloof WG, et al. Oxidation induced crack healing of $\mathrm{Ti}_{3} \mathrm{AlC}_{2}$ ceramics. Scr Mater 2008, 58: 13-16.

[69] Chou IA, Chan HM, Harmer MP. Effect of annealing environment on the crack healing and mechanical behavior of silicon carbide-reinforced alumina nanocomposites. J Am Ceram Soc 1998, 81: 1203-1208.

[70] Korous J, Chu MC, Nakatani M, et al. Crack healing behaviour of silicon carbide Ceramics. $J$ Am Ceram Soc 2000, 83: 2788-2792.

[71] Ando K, Furusawa K, Chu MC, et al. Crack-healing behaviour under stress of mullite/silicon carbide ceramics and the resultant fatigue strength. J Am Ceram Soc 2001, 84: 2073-2078.

[72] Ando K, Chua MC, Tuji K, et al. Crack healing behaviour and high-temperature strength of mullite/SiC composite ceramics. J Europ Ceram Soc 2002, 22: 1313-1319.

[73] Kim YW, Ando K, Chu MC. Crack-healing behaviour of liquid-phase sintered silicon carbide ceramics. J Am Ceram Soc 2002, 86: 465-470.

[74] Liu SP, Ando K. Fatigue strength characteristics of crack-healing materials $-\mathrm{Al}_{2} \mathrm{O}_{3} / \mathrm{SiC}$ composite ceramics and monolithic $\mathrm{Al}_{2} \mathrm{O}_{3}$.J Chin Inst Eng 2004, 27: 395-404.

[75] Zhang YH, Edwards L, Plumbridge WJ. Crack healing in silicon nitride ceramics. J Am Ceram Soc 1998, 81: 1861-1868.

[76] Dey N, Socie DF, Hsia KJ. Modelling static and cyclic fatigue in ceramics containing a viscous grain goundary phase. Acta Metall Mater 1995, 43: 2163-2175.

[77] Barsoum MW. The $\mathrm{M}_{N+1} \mathrm{AX}_{N}$ phases: A new class of solids thermodynamically stable nanolaminates. Progr Solid State Chem 2000, 28: 201-281.

[78] Eklund P, Beckers M, Jansson U, et al. The $\mathrm{M}_{n+1} \mathrm{AX}_{n}$ phases: Materials science and thin-film processing. Thin Solid Films 2010, 518: 1851-1878.

[79] Sun ZM. Progress in research and development on MAX phases: A family of layered ternary compounds. Int Mat Rev 2011, 56: 143-166.

[80] Yang HY, Pei YT, Rao JC, et al. Self-healing performance of $\mathrm{Ti}_{2} \mathrm{AlC}$ ceramic. J Mat Chem 2012, 22: 8304-8313.

[81] Huang XX, Wen GW. Mechanical properties of $\mathrm{Al}_{4} \mathrm{SiC}_{4}$ bulk ceramics produced by solid state reaction. Ceram Int 2007, 33: 453-458.

[82] van der Zwaag S, van Dijk NH, Jonkers HN, et al. Self-healing behaviour in man-made engineering materials: Bioinspired but taking into account their intrinsic character. Phil Trans Roy Soc 2009, 367: 1689-1704.

[83] Li G, Uppu N. Shape memory polymer based self-healing syntactic foam: 3D confined thermomechanical characterization. Compos Sci Technol 2010, 70: 1419-1427.

[84] Kirkby EL, Michaud VJ, Mason JA, et al. Performance of self-healing epoxy with microencapsulated healing agent and shape memory alloy wires. Polymer 2009, 50: 5533-5538.

[85] Sestak J, Berggren G. Study of the kinetics of the mechanism of solid-state reactions at increasing temperatures. Thermochim Acta 1971, 3: 1-12. 
[86] Wakai F, Brakke KA. Mechanics of sintering of coupled grain boundary and surface diffusion. Acta Mat 2011, 59: 5379-5387.

[87] Subramaniam A, Koch CT, Cannon RM, et al. Intergranular glassy films: An overview. Mat Sci Eng 2006, 422: 3-8.

[88] Clarke DR. On the equilibrium thickness of intergranular glass phases in ceramic materials. $J$ Am Ceram Soc 1987, 70: 15-22.

[89] Galmarini S, Aschauer U, Bowen P, et al. Atomistic simulation of Y-doped apha-alumina interfaces. $J$ Am Ceram Soc 2008, 91: 3643-3651.

[90] Chen IW, Xue LA. Development of superplastic ceramics. J Am Ceram Soc 1990, 73: 2585-2609.

[91] Smedskjaer MM, Mauro JC, Yue Y. Ionic diffusion and the topological origin of fragility in silicate glasses. J Chem Phys 2009, 131: 1-9.

[92] Yue YZ. The iso-structural viscosity, configurational entropy and fragility of oxide liquids. $J$ Non-Cryst Solids 2009, 355: 737-744.

[93] Wu WH, Zhang JL, Zhou HW, et al. A method to study the crack healing process of glassformers. Appl Phys Lett 2008, 92: 1918-1921.

[94] Peterson IM, Tien TY. Thermal expansion and glass transition temperatures of Y-Mg-Si- Al-O-N glasses. J Am Ceram Soc 1995, 78: 1977-1979.

[95] Hampshire S, Pomeroy MJ. SiAlON bulk glasses and their role in silicon nitride grain boundaries: Composition-structure-property relationships. $J$ Korean Ceram Soc 2012, 49: 301-307.

[96] Tredway WK, Risbud SH. Melt processing and properties of Barium-Sialon glasses. J Am Ceram Soc 1983, 66: 324-327.

[97] Rocherulle J, Guyader J, Verdier $\mathrm{P}$, et al. Li-Si-AI-O-N and Li-Si-O-N oxynitride glasses study and characterization. J Mat Sci 1989, 24: 4525-4530.

[98] Lofaj F. Localized viscous flow in the oxide and oxinitride glasses by indentation creep. Chem Listy 2011, 105: 198-201.

[99] Becher PF, Lance MJ, Ferber MK. The influence of $\mathrm{Mg}$ substitution for $\mathrm{Al}$ on the properties of SiMeRE oxynitride glasses. J Non-Cryst Solids 2004, 333: 124-128.

[100] Hampshire S. Oxynitride glasses. J Europ Ceram Soc 2008, 28: 1475-1483.

[101] Clarke DR. Grain boundaries in polycrystalline ceramics. Ann Rev Mat Sci 1987, 17: 57-74.

[102] Hampshire S. Oxynitride glasses, their properties and crystallisation - A review. J Non-Cryst Solids 2003, 316: 64-73.
[103] Nichols FA, Mullins WW. Morphological changes of a surface of revolution due to capillarity-induced surface diffusion. J Appl Phys 1965, 36: 1826-1836.

[104] Stüwe HP, Kolednik O. Shape instability of thin cylinders. Acta Metall 1988, 36: 1705-1708.

[105] Kanters J, Eisele U, Rödel J. Cosintering simulation and experimentation: Case study of nano-crystalline zirconia. J Am Ceram Soc 2001, 84: 2757-2763.

[106] Zhang D, Weng G, Gong S, et al. The kinetics of initial stage in sintering process of $\mathrm{BaTiO}_{3}$-based PTCR ceramics and its computer simulation. Mat Sci Eng B 2003, 99: 88-92.

[107] Ferreira Nasciemento ML, Zanotto ED. Diffusion processes in vitreous silica revisited. Phys Chem Glasses: Eur J Glass Sci Techn B 2007, 48: 201-217.

[108] Roberston WM. Thermal etching and grain boundary grooving silicon ceramics. J Am Ceram Soc 1981, 64: 9-13.

[109] Kraft Riedel T. Numerical simulation of solid state sintering: Model and application. J Europ Ceram Soc 2004, 24: 345-361.

[110] Demirskyi D, Ragulya A, Agrawal D. Initial stage sintering of binderless tungsten carbide powder under microwave radiation. Ceram Int 2011, 37: 505-512.

[111] Orlando R, Pisani C, Ruiz E, et al. Ab-initio study of the bare and hydrated (001) surface of tetragonal zirconia. Surf Sci 1992, 275: 482-492.

[112] Parikh NM. Effect of atmosphere on surface tension of glass. J Am Ceram Soc 1958, 41: 18-22.

[113] Hara S, Izumi S, Kumagai T, et al. Surface energy, stress and structure of well-relaxed amorphous silicon: A combination approach of ab initio and classical molecular dynamics. Surf Sci 2005, 585: 17-24.

[114] Idrobo JC, Iddir $\mathrm{H}$, Ögüt $\mathrm{S}$, et al. $\mathrm{Ab}$ initio structural energetics of $\beta-\mathrm{Si}_{3} \mathrm{~N}_{4}$ surfaces. Phys Rev B 2005, 72: 241301 .

[115] Tsuruta K, Totsuji H, Totsuji C. Neck formation processes of nanocrystalline silicon carbide: A tight-binding molecular dynamics study. Phil Mag Lett 2001, 81: 357-366.

[116] Tseng TY, Nalwa HS. Handbook of Nanoceramics and Their Based Nanodevices. Valencia: Amercian Scientific Publishers, 2006.

[117] Harmer MP, Chan HM, Miller GA. Unique opportunities for microstructural engineering with duplex and laminar ceramic composites. $J \mathrm{Am}$ Ceram Soc 1992, 75: 1715-1728. 
[118] Sun J, Simon SL. The melting behavior of aluminum nanoparticles. Thermochim Acta 2007, 463: 32-40.

[119] Nanda KK, Maisels A, Kruis FE, et al. Higher surface energy of free nanoparticles. Phys Rev Lett 2003, 91: 102-106.

[120] Tsantilis S, Briesen H, Pratsinis SE. Sintering time for silica particle growth. Aerosol Sci Techn 2001, 34: 237-246.

[121] Butyagin PY. Mechanical disordering and reactivity of solids. In Advances in Mechanoche Mistry, Physical and Chemical Processes under Deformation. Harvard Acad Publ, 1998: 91-165.

[122] Tromanns D, Meech JA. Enhanced dissolution of minerals: Stored energy, amorphism and mechanical activation. Min Eng 2001, 14: 1359-1377.

[123] Song CM, Xu ZM, Wang YJ, et al. Synthesis and electrochemical characterization of $\mathrm{LiMn}_{2-x} \mathrm{Al}_{x} \mathrm{O}_{4}$ powders prepared by mechanical alloying and rotary heating. Electrochemis Try Commu 2003, 5: 907-912.

[124] Couchman PR, Jesser WA. Thermodynamic theory of size dependence of melting temperature in metals. Nature 1977, 269: 481-483.

[125] Lam NQ, Okamoto PR, Li M. Disorder-induced amorphization. J Nucl Mat 1997, 251: 89-97.

[126] Fecht HJ. Defect-induced melting and solid-state amorphization. Nature 1992, 356: 133-135.

[127] Nanko M, Maruoka D, Nguyen TD. Crack-healing function of metal $/ \mathrm{Al}_{2} \mathrm{O}_{3}$ hybrid materials. IOP Conf Ser: Mater Sci Eng 2011, 18: 082-105.

[128] Song GM, Sloof WG, Li SB, et al. Crack healing of advanced machinable high temperature $\mathrm{Ti}_{3} \mathrm{AlC}_{2}$ ceramics. In Proc.1st Intern Conf on Self Healing Materials 2007: 1-9.

[129] Yang HJ, Pei YT, Rao JC, et al. High temperature healing of $\mathrm{Ti}_{2} \mathrm{AlC}$ : On the origin of inhomogeneous oxide scale. Scr Mat 2011, 65: 135-138.

[130] Li SB, Song GM, Kwakernaak K, et al. Multiple crack healing of a $\mathrm{Ti}_{2} \mathrm{AlC}$ ceramic. J Europ Ceram Soc 2012, 32: 1813-1820.

[131] Barsoum MW, Farber L. Room-temperature deintercalation and self-extrusion of $\mathrm{Ga}$ from $\mathrm{Cr}_{2}$ GaN. Science 2011, 284: 937-939.

[132] Liu B, Wang JY, Zhang J, et al. Theoretical investigation of A-element atom diffusion in $\mathrm{Ti}_{2} \mathrm{AlC}$ $(\mathrm{A}=\mathrm{Sn}, \mathrm{Ga}, \mathrm{Cd}, \mathrm{In}$, and $\mathrm{Pb})$. Appl Phys Lett 2009, 94: 1819-1825.

[133] Greil P. Advancements in polymer-filler derived ceramics. J Korean Ceram Soc 2012, 49: 279-286.

[134] Schlier L, Travitzky N, Gegner J, et al. Surface strengthening of extrusion formed polymer/filler derived ceramic composites. J Ceram Sci Techn 2012, 3: 12-18.

[135] Erny T. Formation and properties of polymer derived composite ceramics of the system $\mathrm{MeSi}_{2}$ / polysiloxane. Ph.D. Thesis. Erlangen, Germany: Univ Erlangen-Nuernberg, 1996.

[136] Colombo P, Mera G, Riedel R, et al. Polymer-derived ceramics: 40 years of research and innovation in advanced ceramics. $J$ Am Ceram Soc 2010, 93: 1805-1837.

[137] Larker R. Reaction sintering and properties of silicon oxynitride densified by hot isostatic pressing. J Am Ceram Soc 1992, 75: 62-55.

[138] Riley FL. Silicon nitride and related materials. J Am Ceram Soc 2000, 83: 245-265. 